\title{
Role of Aldehyde Oxidase and Xanthine Oxidase in the Metabolism of Purine-Related Drugs
}

\author{
Mohammad-Reza Rashidi and Roghiyeh Pashaei-Asl \\ Research Center for Pharmaceutical Nanotechnology, \\ Tabriz University of Medical Sciences, Tabriz,
}

Iran

\section{Introduction}

Purines are natural compounds that are found in all of the body's cells. They are the most widely distributed kind of N-heterocyclic substances in nature. Purines provide part of the chemical structure of some important co-enzymes and the genes of plants and animals. These compounds also participate in membrane signal transduction, translation and protein synthesis and in the form of purine nucleosides act as neurotransmitters in a variety of tissues. Purine base is also present in the structure of some important drugs such as 6-mercaptopurine (6-MP) and azathioprine (AZT). In addition, it can be found as a nucleobase in some synthetic nucleoside analogues with various pharmacological effects including antiviral and antitumor properties and numerous nucleoside analogues and their prodrugs were developed for cancer chemotherapy, treatment of patients with infections of human immunodeficiency virus (HIV) and infections caused by herpes and hepatitis viruses.

Different enzymes can participate in the metabolism of a drug and alter its function. Aldehyde oxidase (EC 1.2.3.1: aldehyde: oxygen oxidoreductase, AO), and xanthine oxidase (EC 1.17.3.2: xanthine: oxygen oxidoreductase, $\mathrm{XO}$ ) which are collectively referred as "molybdenum hydroxylases", are two important cytosolic enzymes that are widely distributed throughout the animal kingdom. They are involved in the metabolism of an extensive range of exogenous and endogenous compounds with physiological, pharmacological and toxicological relevance (Beedham, 2010; Rashidi \& Nazemiyeh, 2010). The reactions catalyzed by AO and XO usually involve a nucleophilic attack at an electron-deficient carbon atom adjacent to a ring nitrogen atom in N-heterocyclic compounds or found within an aldehyde group. Therefore, purines as N-heterocyclic compounds can act as a substrate for both AO and XO (Hall \& Krenitsky, 1986; Krenitsky et al, 1972, 1986; Rashidi et al., 1997, 2007). In spite of having many physicochemical properties in common, $\mathrm{AO}$ and $\mathrm{XO}$ have different substrate specificities and product regiospecificities. In addition, pronounced species variation is present in the levels of molybdenum hydroxylases activity, in particular in that of AO (Alfaro et al., 2009; Jones et al., 1987; Krenitsky et al., 1984; Rashidi et al., 1997). Therefore, a metabolic pathway 
mediated by AO or XO could be completely different. This will be more pronounced for those compounds that have several sites for oxidation by these two oxidative enzymes. Purine nucleus has three sites that could be oxidized by molybdenum hydroxylases. It would be difficult, thus, to predict which metabolite will be produced from a purinebased drug by $\mathrm{AO}$ or $\mathrm{XO}$, and the recognition of $\mathrm{AO}$ and $\mathrm{XO}$ contribution in the metabolism of this group of drugs will be a subject for scientific studies. This review highlights the involvement of $\mathrm{AO}$ and $\mathrm{XO}$ in the metabolism of important purine related drugs focusing on recent studies.

\subsection{Biological and pharmacological importance of purines}

Purines are an important group of nitrogen-containing compounds that are present in all forms of plant and animal life and play a vital role in biological processes. They serve as the source of cellular energy in ATP and together with pyrimidine, are the building blocks of DNA and RNA. Purines also participate in the structure of the co-enzymes (e.g. NAD $\mathrm{NADP}^{+}$and FAD) and they are involved in membrane signal transduction, translation and protein synthesis (GTP, cAMP, cGMP, RNA). Over the last decades, a great deal of attention has been focused on the extracellular functions of purine nucleosides as neurotransmitters in a variety of tissues and different types of specific membrane purinergic receptors have been recognized (Di Iorio et al., 1998; Ralevic, 2009).

Purine nucleus is also present in the structure of some important drugs such as 6thioguanine (6-TG), 6-MP and AZT. In addition, it can be found as a nucleobase in some synthetic nucleoside analogues which are structurally similar to natural nucleosides. Many nucleoside analogues have antiviral and antitumor properties. During the last decades, numerous nucleoside analogues and their prodrugs were developed for cancer chemotherapy, treatment of patients with infections of human immunodeficiency virus (HIV) and infections caused by herpes and hepatitis viruses (Li et al., 2008). In spite of having excellent pharmacological activity, they often suffer from a poor oral bioavailability due to low intestinal absorption. Therefore, intense research efforts have been focused on developing nucleoside analogues prodrugs, mainly in the acyclic form, to improve oral absorption (Li et al., 2008).

\subsection{Chemistry of purine}

In 1776, uric acid was isolated in a pure form from urinary calculi (stones), although the identification of its structure was not made until about 100 years later. It was this event that later was commemorated in the generic name, "purine" (from purum uricum) for the heterocyclic system (Hitchings, 1978). Xanthine and hypoxanthine were recognized as other members of the system in 1838 and 1850 respectively (Hitchings, 1978). In 1889, the term "nucleic acid" was introduced by Altmann and general methods for isolation of nucleic acids from various sources were developed by this investigator (Hurst, 1980). Then, purines and pyrimidines were discovered in nucleic acids and isolated from calf thymus nucleic acid in 1894 (Hurst, 1980).

The purine nucleus consists of fused pyrimidine and imidazole rings having the numbering system shown in Fig. 1 it is an aromatic compound with -deficient ring 
system; therefore, all its carbon atoms are susceptible towards nucleophilic attack and are deactivated towards electrophilic attack. Because of the electron-attracting character of the $\mathrm{C}=\mathrm{N}$ moiety, the 2-, 6- and 8-sites favor nucleophilic attack, although the 8position would be expected to be less electron deficient than the two other sites due to the electron-releasing character of the $-\mathrm{NH}$ - moiety present in imidazole ring. The calculated electron densities of the various sites in purine are given in Figure 1. Purine is a weak base with an overall $\mathrm{pKa}=2.3$ (Joule, 1995). According to ${ }^{13} \mathrm{C}$ NMR studies all three protonated forms are present in solution but it is suggested that the predominant cation is formed by $\mathrm{N}^{1}$ protonation (Joule, 1995). Purine is also a weak acid with a pKa of 8.9 (Joule, 1995).
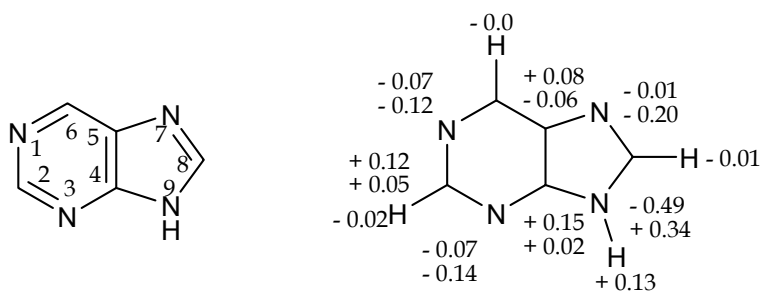

Fig. 1. The numbering system and electron densities of purine. Upper and lower numbers in (b) are - and -charges respectively (Shaw, 1984)

\subsection{Purines as substrates for aldehyde oxidase and xanthine oxidase}

Different enzymes can participate in the metabolism of a drug either through conversion of a prodrug to an active form or elimination of a drug via its metabolic pathway. AO and XO as two drug metabolizing enzymes can utilize purines as their substrates (Hall \& Krenitsky, 1986; Krenitsky et al, 1972, 1986; Rashidi et al., 1997, 2007). They have many properties in common; both enzymes are large homodimeric proteins with a molecular mass of $\sim 300,000$ $\mathrm{Da}$, composed of two identical subunits. Each subunit contains one atom of molybdenum, one molecule of enzyme-bound flavin adenine dinucleotide (FAD) and two iron-sulfur (2Fe-2S) centers. In spite of these similarities and the existence of an overlap in substrate utilization between $\mathrm{AO}$ and $\mathrm{XO}$, they have different substrate specificities and product regiospecificities. As it was mentioned before, molybdenum hydroxylases can catalyze the oxidation of a wide range of aldehydes and N-heterocyclic compounds (Beedham, 2010; Rashidi \& Nazemiyeh, 2010). Purines are among those N-heterocyclic compounds that may be oxidized by $\mathrm{AO}$ and $\mathrm{XO}$ either as a prodrug converted to its active form (Krenitsky et al., 1984; Rashidi et al., 1997) or during their catabolic pathways (Rashidi et al., 2007). However, the manner of oxidation by these two enzymes could be different from one compound to another.

\subsection{Metabolism of endogenous purines}

Purine metabolism in man may be divided into four interfacing compartments which are illustrated in Fig. 2 (Palella \& Fox, 1991). 
(1)

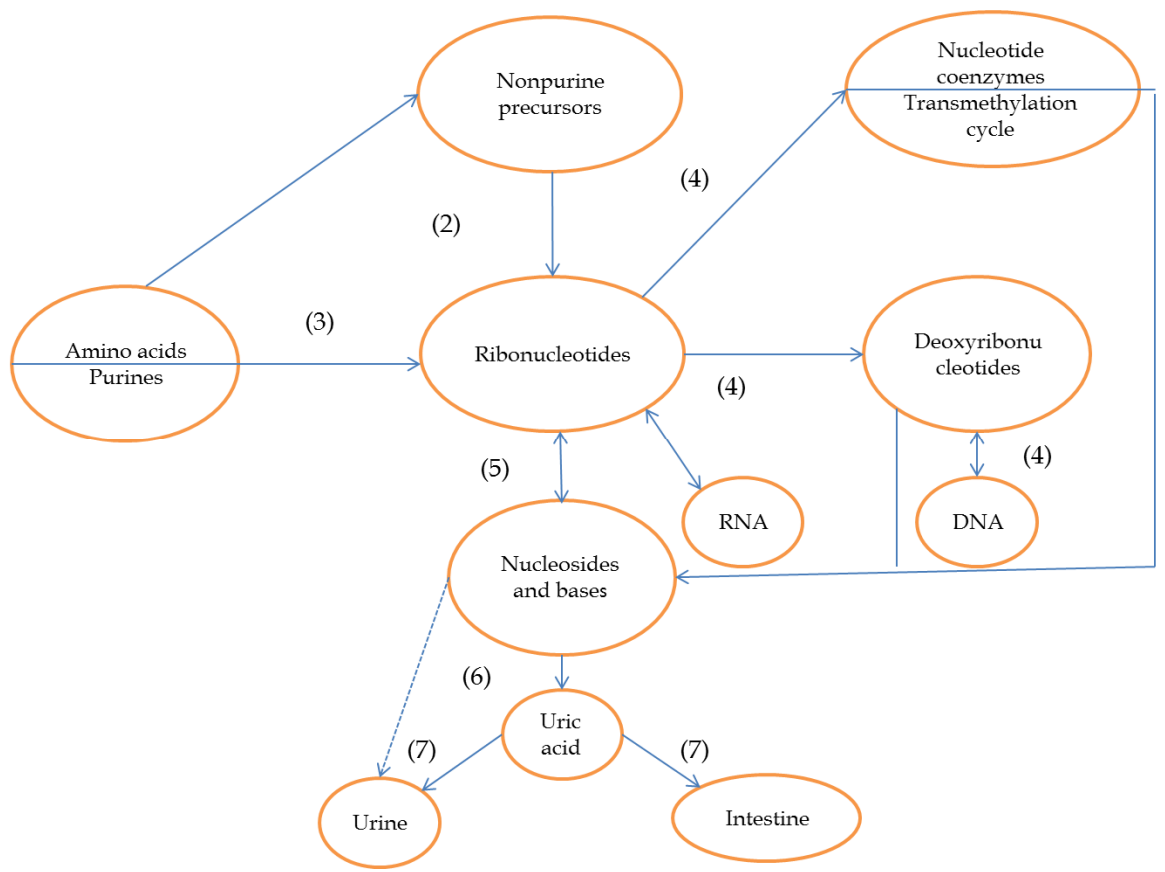

(5)

Fig. 2. Overview of purine metabolism in man (Palella \& Fox, 1991)

a. De novo purine synthesis: The biosynthetic pathway through which non-purine precursors are combined to form the purine ring is referred to as de novo purine synthesis. These non-purine precursors are provided through dietary intake of amino acids (1). The first reaction in this synthetic process is the formation of 5phosphoribosyl-1-pyrophosphate which is finally converted to inosine- 5 '-monophosphate (IMP) in a ten step pathway (2).

b. Nucleotide interconversion: Once IMP is formed it may be metabolized to other purine ribonucleotides such as AMP and GMP by interconversion pathways (3).

c. Salvage of performed purine bases: These ribonucleotides may be converted to diphosphate and triphosphate forms which serve as essential substrates for variety of pathways (4), or to be broken down to purine bases or nucleosides (5).

d. Degradation: As a final step in human purine metabolism, nucleosides and purine bases are metabolised to uric acid (6) which is excreted primarily in urine with small amounts excreted into intestine thereby bacterial uricolysis occurs (7). The conversion of hypoxanthine to xanthine and xanthine to uric acid is catalyzed by $\mathrm{XO}$.

\section{Purine-related drugs and their metabolism by molybdenum hydroxylases}

\subsection{Thiopurines: 6-mercaptopurine, azathioprine and 6-thioguanine}

Thipurines, 6-MP, AZT and 6-TG, are the analogues of purine nucleosides that serve as the backbone of current childhood acute leukemia treatment. They have also been effective 
immunosuppressive agents for the past half a century and remain the immunosuppressive of choice for Crohn's disease (Ansari et al., 2008; Fotoohi et al., 2010). In the early 1940s, the first studies on purine analogues as antimetabolites were begun by Hitchings and his group in which 8-azaguanine and 2,6-diaminopurine were found to possess marked anticancer activity in experimental tumors (Elion et al., 1951). Subsequently, 6-MP was synthesized by Elion and Hutchins in 1951 and found to have a high order of activity against human leukemia (Elion et al., 1952); it was successfully employed in the treatment of leukemia in man in 1953. This discovery was an important point in the development of antineoplastic and immunosuppressive agents. In 1958, the immunosuppressive activity of 6-MP in rabbits was demonstrated by Schwartz et al. (1958). Shortly, 6- (1-methyl-4-nitro-5-imidazolyl) thiopurine, AZT, was synthesized by the Hitchings-Elion laboratory and shown that this analogue of 6-MP acts as a pro-drug and is reduced non-enzymatically in body to 6-MP which is converted by sensitive neoplasms to the active form 6-thioinosinate by hypoxanthine-guanine phosphoribosyl-transferase (Van Scoik et al., 1985). AZT has a higher therapeutic index than 6-MP (Van Scoik et al., 1985). AZT has more potent immunosuppressive effect than 6-MP and is preferred drug to prevent or delay graft rejection and treat rheumatoid arthritis (Chabner et al., 2001). 6-MP together with methotrexate are the drugs of choice in the treatment of childhood acute lymphocytic leukemia, especially in those cases where prolonged duration of remission is required (Knoester et al., 1993; Van Scoik et al., 1985); however, this thiopurine is not effective for the treatment of chronic lymphocytic leukemia, Hodgkings disease or other lymphomas/carcinomas (Rider, 2008).

Although thiopurines have been used for over 50 years, many aspects of their complex pharmacology and metabolism remain unclear. However, it has been suggested that (Zimm et al., 1984; Chabner et al., 2001) in the cell, 6-MP is converted first to thioinosinic acid, by hypoxanthine-guanine phosphoribosyl-transferase which is then metabolized to thioguanine ribonucleotide and deoxyribonucleotide; incorporation of these compounds into RNA and DNA results in the antitumour effect of the drug. In addition, thioinosinic acid can be methylated to 6-methylthioinosinate which like thioinosinic acid is able to inhibit glutamine-5-phosphoribosylpyrophosphate amidotransferase, the first enzyme unique to the de novo pathway for purine ribonucleotide synthesis.

The oral bioavailibility of 6-MP in man is low and highly variable (Knoester et al., 1993; Meerten et al., 1995), however, this is the usual rout of administration. The mechanism for this variability is not fully known but it may be due to a combination of differences in the rate of absorption, distribution, elimination and first-pass metabolism of drug (Knoester et al., 1993). After intravenous injection, 6-MP undergoes rapid cellular uptake, hepatic metabolism, and renal excretion. Approximately $50 \%$ of an administered dose of the drug is excreted in the urine within 24 hours, with $22 \%$ eliminated as unchanged drug (Rider, 2008).

6-MP, after administration, may enter into either anabolic or catabolic metabolic pathways (Lennard et al., 1991; Van Scoik et al., 1985). The anabolic pathway is responsible for conversion of 6-MP to its active form, whereas the drug is degraded to inactive forms in the catabolic pathway via two major inactivation routes (Fig. 3). One is thiol methylation, which is catalyzed by the enzyme thiopurine S-methyltransferase, to form the inactive metabolite methyl-6-mercaptopurine. The second route is thought to involve the initial oxidation of 6MP to 8-oxo-6-MP followed by conversion to 6-thiouric acid (Elion, 1967; Van Scoik et al., 
1985). However, Zimm et al., (1984) have identified 6-thioxanthine in the urine samples of some patients who received 6-MP by intravenous infusion which may indicate that 6-MP is converted to 6-thiouric acid via 6-thioxanthine. The oxidative inactivation of 6-MP has been attributed to $\mathrm{XO}$ activity in intestinal mucosa and liver. The $\mathrm{Km}$ value for the oxidation of 6MP by calf liver and bovine milk xanthine oxidase (BMXO) is 20-30 $\mu \mathrm{M}$ (Chalmers et al., 1969; Krenitsky et al., 1972). 6-MP is also a substrate for rabbit liver AO with a reported Km of $1.6 \mathrm{mM}$ (Hall \& Krenitsky, 1986). The second catabolic pathway for 6-MP is methylation of the sulphur atom catalyzed by thiopurine methyltransferase. 6-Methylmercaptopurine then undergoes oxidation at position 8 catalyzed by XO and/or AO (Van Scoik et al., 1985); the difference in metabolite profile between oral and intravenous administration may be indicative of the significant role of AO in 8-hydroxylation (Beedham, 2002). These metabolic pathways are illustrated in Fig. 3.

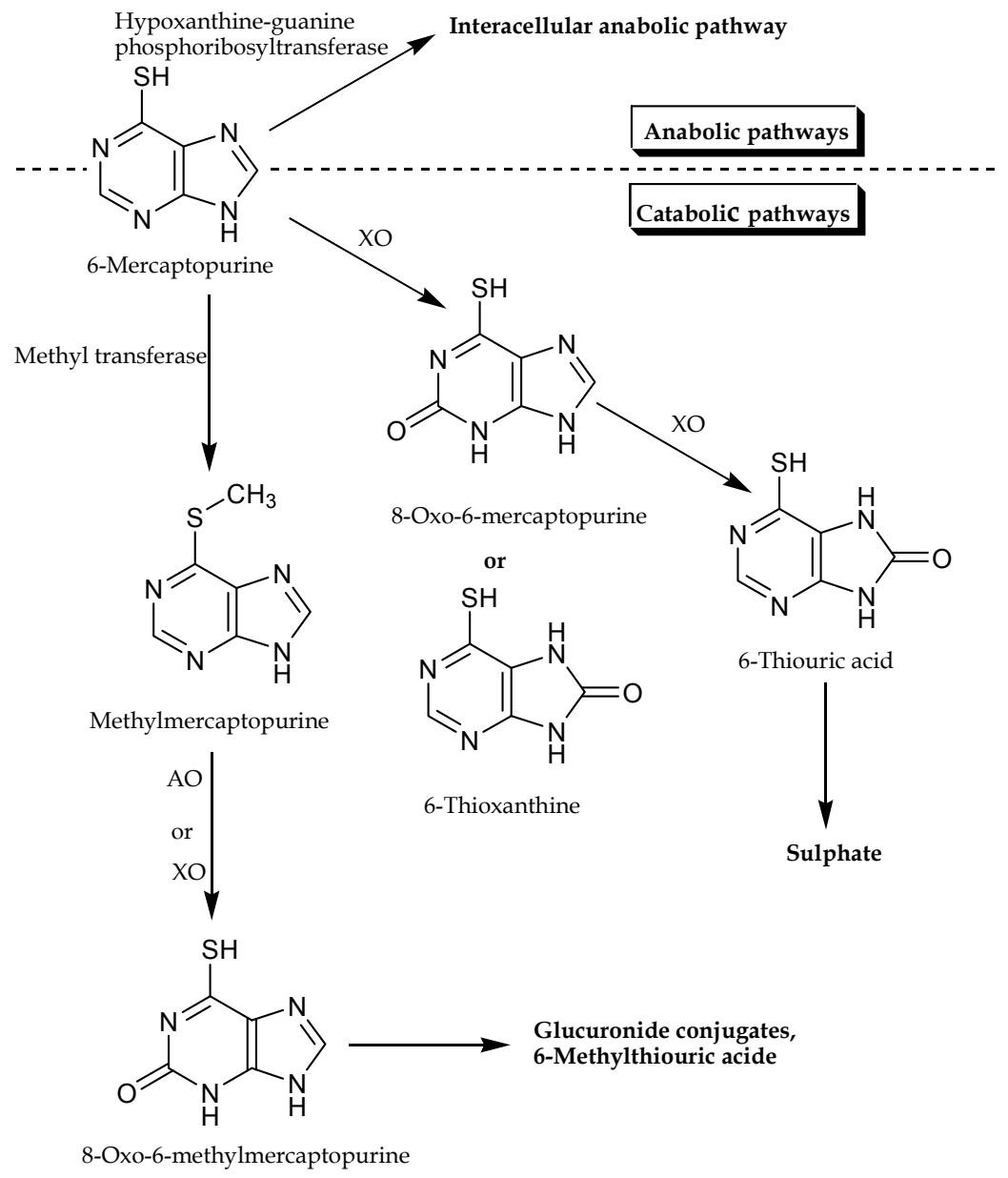

Fig. 3. Proposed metabolic pathways for 6-mercaptopurine (6-MP) (Van Scoik et al., 1985; Zimm et al., 1984). AO: aldehyde oxidase, $\mathrm{XO}$ : xanthine oxidase 
Although 6-thiouric acid has been detected as the major metabolite of 6-MP after oral administration of drug (Elion, 1967; Van Scoik et al., 1985; Zimm et al., 1984), there is no direct evidence in the involvement of molybdenum hydroxylases in these oxidative reactions and the results obtained from in vitro studies are controversial. 8-Oxo-6-MP (Elion, 1967; VanScoik et al., 1985), 6-methylmercapto-8-hydoxypurine (Keuzenkamp-Jansen et al., 1996) and 6-thioxanthine (Zimm et al., 1984), all have been suggested to be the intermediate in the conversion of 6-MP to 6-thiouric acid. Recently, Rashidi et al. (2007) have demonstrated that 6- MP is more likely oxidized to 6-thiouric acid via 6-thioxanthine rather than 8-oxo-6-MP. The first step which is the rate limiting step is catalyzed solely by $\mathrm{XO}$, whereas both $\mathrm{XO}$ and $\mathrm{AO}$ are involved in the oxidation of 6-thiouric acid to 6-thiouric acid (Fig. 4).

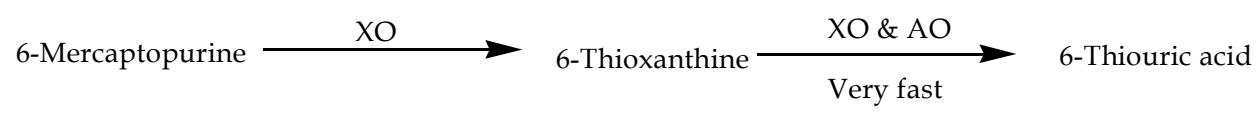

Fig. 4. Proposed metabolic pathway for the oxidation of 6-mercaptopurine by partially purified guinea pig liver fractions (Rashidi et al., 2007). AO: aldehyde oxidase,

XO: xanthine oxidase

The metabolism of 6-TG is very similar to that of 6-MP, however, there is a clinically important difference between catabolic pathway of these two thiopurines (Fig. 5). Unlike 6MP which is first metabolized to 6-thioxanthine by $\mathrm{XO}$ and then 6-thiouric acid by both $\mathrm{XO}$ and AO (Rashidi et al., 2007), 6-TG must first be metabolized by guanine deaminase (guanase) to 6-thioxanthine, which is then metabolized to 6- thiouric acid (Evans \& Relling, 1994; Hogarth et al., 2008). As guanase is not as abundant as XO, more of 6-TG is directly activated to thioguanine nucleotides without oxidation to the inactive metabolite, 6-thiouric acid (Hogarth et al., 2008). This could be a reason for some clinical findings (Lennard et al., 1993) indicating that in children with acute lymphoblastic leukemia, significantly higher concentrations of thioguanine nucleotides are achieved with oral 6-TG therapy compared with oral 6-MP therapy (Evans \& Relling, 1994).

In addition, taking into account the important role of $\mathrm{XO}$ in the catabolic pathway of 6-MP, co-administration of 6-MP and XO inhibitors such as allopurinol can lead to severe forms of mercaptopurine toxicity and dosage modification of the drug is necessary, whereas in the case of 6-TG dosage modification is not warranted, because the first step of drug inactivation is not catalyzed by XO (Hande \& Garrow, 1996).

$\mathrm{AO}$ is also involved in the metabolism of 6-TG (Fig. 5). According to Kitchen et al. (1999), 6TG can be oxidized to 8-hydroxythioguanine by AO. 8-Hydroxythioguanine has been found to be the predominant circulating metabolite in patients receiving continuous i.v. infusion of thioguanine and is likely generated by the action of AO (Kitchen et al., 1999).

AZT can also undergo two different metabolic routes. In the first route, AZT is extensively converted to 6-MP which is then metabolized as in Fig. 6. In the second route, AZT may be directly oxidized to 8-oxo-azathioprine, catalyzed by AO. Cleavage of 8-oxo-azathioprine by glutathione or other nucleophilic compounds gives 8-oxo-6-mercaptopurine which may then be oxidized to 6-thiouric acid by XO (Fig. 6). 


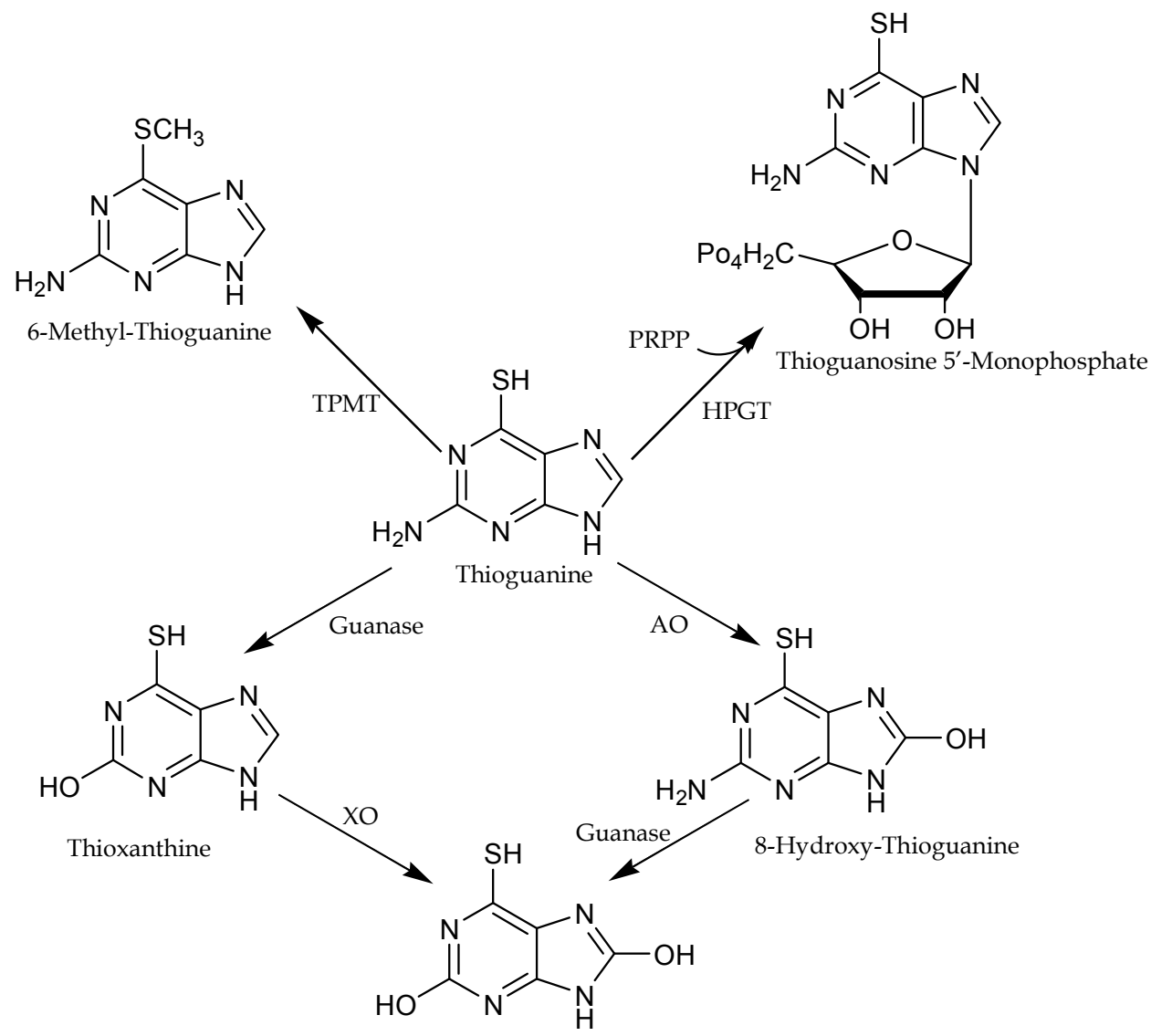

Thiouric Acid

Fig. 5. Metabolic pathways of 6-TG. PRPP: phosphoribosyl pyrophosphate, HPGT:

hypoxanthine-guanine phosphoribosyl transferase, TPMT: thioguanosine monophosphate, AO: aldehyde oxidase, XO: xanthine oxidase (from: Kitchen et al., 1999)

The $\mathrm{Km}$ value for the oxidation of azathioprine by rabbit liver AO is $80 \mu \mathrm{M}$ (Chalmers et al., 1969), whereas azathioprine is very poor substrate for XO such that kinetic constants have been measured competitively against the oxidation of 6-methylaminopurine catalyzed by human liver $\mathrm{XO}\left(\mathrm{K}_{\mathrm{i}}=340 \mu \mathrm{M}\right)$ (Krenitsky et al., 1986). Therefore, it is likely that AZT is oxidized by AO in vivo if the drug comes in contact with the enzyme (Chalmers et al., 1969). It is estimated that the effects of $\mathrm{XO}$ and $\mathrm{AO}$ activity leaves only about $16 \%$ of the total dose of 6-MP available for systemic distribution (Fotoohi et al., 2010). 


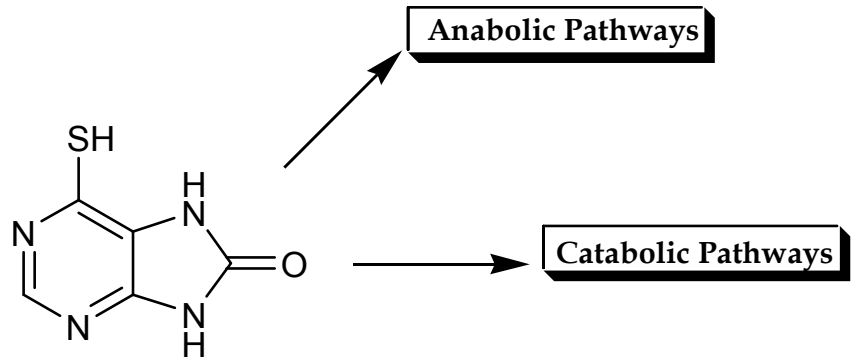

6-Mercaptopyrine<smiles>Cn1cnc([N+](=O)[O-])c1Sc1ncnc2[nH]cnc12</smiles>

Azathioprine<smiles>Cn1cnc([N+](=O)[O-])c1Sc1ncnc2[nH]c(=O)[nH]c12</smiles>

8-Oxo-Azathioprine<smiles>O=c1[nH]c2ncnc(S)c2[nH]1</smiles>

6-Thiouric acid

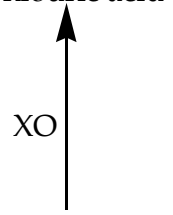

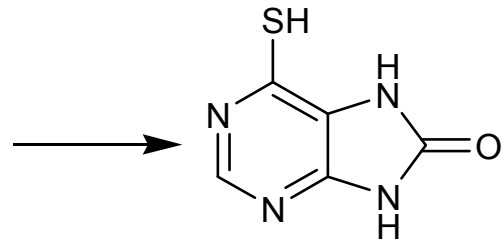

8-Oxo-6-Mercaptopurine

Fig. 6. The metabolic pathways for azathioprine (Van Scoik et al., 1985). AO: aldehyde oxidase, $\mathrm{XO}$ : xanthine oxidase 


\subsection{Famciclovir}

Famciclovir 2-[2-(2-Amino-9H-purin-9-yl) ethyl]-1,3-propanediol diacetate (ester) is a synthetic guanine derivative which is metabolized to the potent antiviral compound penciclovir. Penciclovir is active against herpes simplex virus (HSV) types 1 and 2, varicella zoster virus (VZV), Epstein-Barr virus (EBV), and hepatitis B (Perry \& Wagstaff, 1995).

The mechanism of action of penciclovir is similar to that of aciclovir. Both drugs are selectively phosphorylated in virus-infected cells to a monophosphate ester by thymidine kinase, followed by further phosphorylation to a triphosphate ester which inhibits virus DNA polymerases (Vere Hodge \& Cheng, 1993). However, the concentration of triphosphate ester of penciclovir within infected cells is higher than that of aciclovir and it has a more prolonged intracellular half-life in cells infected with HSV (10-20 hours) and VZV (7-14 hours) compared to aciclovir triphosphate (1 hour) (Perry \& Wagstaff, 1995; Vere Hodge \& Cheng, 1993). Like aciclovir, penciclovir has very low oral bioavailibility, but its prodrug, famciclovir, is absorbed rapidly and extensively after oral administration, and little or no parent compound can be detected in plasma or urine (Mondal, 2008). The absolute bioavailability of penciclovir is about 77\% (Pue \& Benet, 1993), which is about four times higher than that of aciclovir (Murray, 1995).<smiles>CC(=O)OCC(CCn1cnc2cnc(N)nc21)CCn1cnc2cnc(N)nc21</smiles>

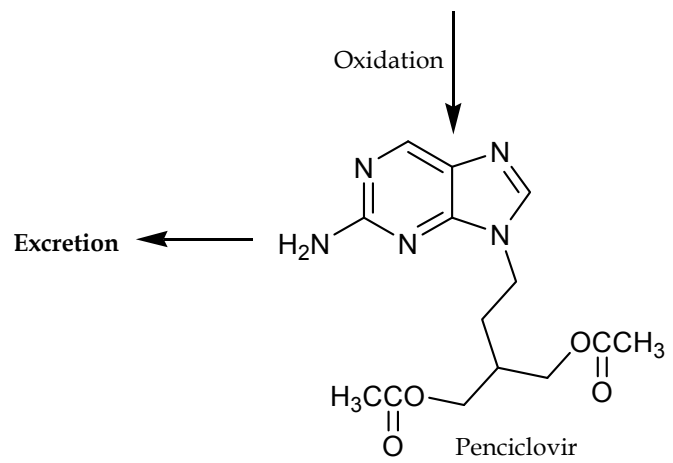

Fig. 7. The major metabolic pathway of famciclovir in man (Vere Hodge et al., 1989)

Metabolism of famciclovir involves sequential hydrolysis of both acetyl groups to give 6deoxypenciclovir which can be oxidized to penciclovir (Fig. 7); however, both in vivo and in 
vitro studies have also shown that penciclovir is the major metabolite of famciclovir metabolism (Pue \& Benet, 1993; Pue et al., 1994; Rashidi et al., 1997). Although the oxidative step was initially attributed to $\mathrm{XO}$, on the basis of studies performed with 6-deoxyaciclovir and a structural similarity between 6-deoxypenciclovir and guanine which is a substrate of XO (Harrell et al., 1993; Krenitsky et al., 1984; Vere Hodge et al., 1989), later studies demonstrated that $\mathrm{AO}$ is the major enzyme in oxidative conversion of famciclovir to penciclovir (Clarke et al., 1995; Rashidi et al., 1997).

According to Rashidi et al. (1997), both famciclovir and 6-deoxypenciclovir are predominantly oxidized at carbon 6 by human, guinea pig and rat hepatic AO, whereas the major metabolites with rabbit enzyme are 8-oxo- and 6-oxo-derivatives with the former metabolite having higher contribution. 6-Deoxypenciclovir is oxidized only at the 6-position by rat liver and BMXO. Famciclovir is a better substrate than 6deoxypenciclovir for hepatic AO from all species tested (Table 1). The oxidation rate of both compounds is comparable with probe substrates of $\mathrm{AO}$ such as phenanthridine and phthalazine (Rashidi et al., 1997).

\begin{tabular}{|c|c|c|c|c|c|c|}
\hline \multirow[b]{2}{*}{ Enzyme fraction } & \multicolumn{3}{|c|}{ 6-Deoxypenciclovir } & \multicolumn{3}{|c|}{ Famciclovir } \\
\hline & $\begin{array}{c}\mathrm{K}_{\mathrm{m}} \\
(\mathrm{mM})\end{array}$ & $\begin{array}{c}\mathrm{V}_{\max } \\
(\mathrm{nmol} / \mathrm{mg} / \mathrm{min})\end{array}$ & $\begin{array}{c}\mathrm{V}_{\max } / \mathrm{K}_{\mathrm{m}} \\
(\mathrm{ml} / \mathrm{min} / \mathrm{mg})\end{array}$ & $\begin{array}{c}\mathrm{K}_{\mathrm{m}} \\
(\mathrm{mM})\end{array}$ & $\begin{array}{c}\mathrm{V}_{\max } \\
(\mathrm{nmol} / \mathrm{mg} / \mathrm{min})\end{array}$ & $\begin{array}{c}\mathrm{V}_{\max } / \mathrm{K}_{\mathrm{m}} \\
(\mathrm{ml} / \mathrm{min} / \mathrm{mg})\end{array}$ \\
\hline $\begin{array}{l}\text { Human Liver AO } \\
(\mathrm{N}=1-2)\end{array}$ & 0.42 & 16 & 0.038 & 0.15 & 61 & 0.407 \\
\hline $\begin{array}{l}\text { Guinea pig liver } \\
\text { AO }(\mathrm{N}=3-5)\end{array}$ & $\begin{array}{l}0.41 \pm \\
0.01^{\text {a }}\end{array}$ & $209 \pm 38$ & 0.510 & $0.17 \pm 0.01$ & $439 \pm 48$ & 2.582 \\
\hline $\begin{array}{l}\text { Rabbit liver AO } \\
(\mathrm{N}=2)\end{array}$ & 0.44 & 114 & 0.259 & & $\mathrm{ND}^{\mathrm{b}}$ & \\
\hline $\begin{array}{l}\text { AO-Active rat } \\
\text { enzyme }(\mathbf{N}=3)^{\text {a }}\end{array}$ & $0.37 \pm 0.05$ & $26 \pm 6$ & 0.070 & $0.08 \pm 0.02$ & $41 \pm 10$ & 0.506 \\
\hline $\begin{array}{l}\text { AO-Deficient rat } \\
\text { enzyme }(\mathrm{N}=3)^{\mathrm{a}}\end{array}$ & $0.26 \pm 0.01$ & $4 \pm 2$ & 0.015 & & $N R^{c}$ & \\
\hline BMXO (N = 2) & 0.90 & 155 & 0.172 & & NR & \\
\hline
\end{tabular}

a Mean \pm SD

${ }^{b}$ ND: Not determined

cNR: No reaction

Table 1. Kinetic parameters for 6-oxo-metabolite formation by partially purified guinea pig, human, rabbit, rat liver aldehyde oxidase $(\mathrm{AO})$ and bovine milk xanthine oxidase (BMXO) determined by HPLC (Rashidi et al 1997) 
Although 6-deoxypenciclovir is oxidized very slowly by rat liver $\mathrm{XO}$ and $\mathrm{BMXO}$, famciclovir did not serve as a substrate for either enzyme. In Figures 8-10, the metabolic pathways of famciclovir with different enzyme fractions have been illustrated.

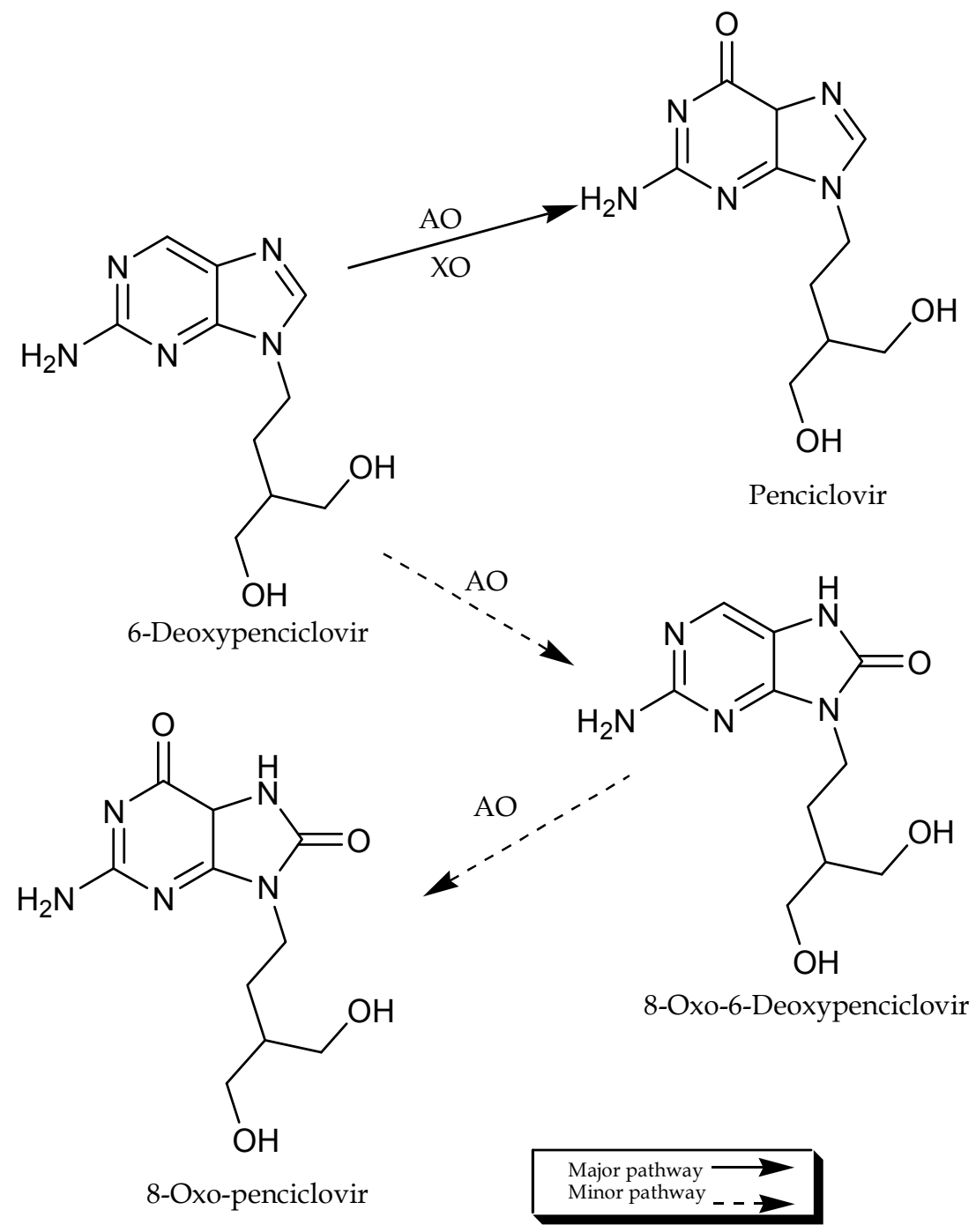

Fig. 8. The oxidative metabolic pathways of 6-deoxypenciclovir catalyzed by partially purified guinea pig, aldehyde oxidase-active rat and human liver fractions (Rashidi, 1996; Rashidi et al., 1997). AO: aldehyde oxidase, XO: xanthine oxidase 

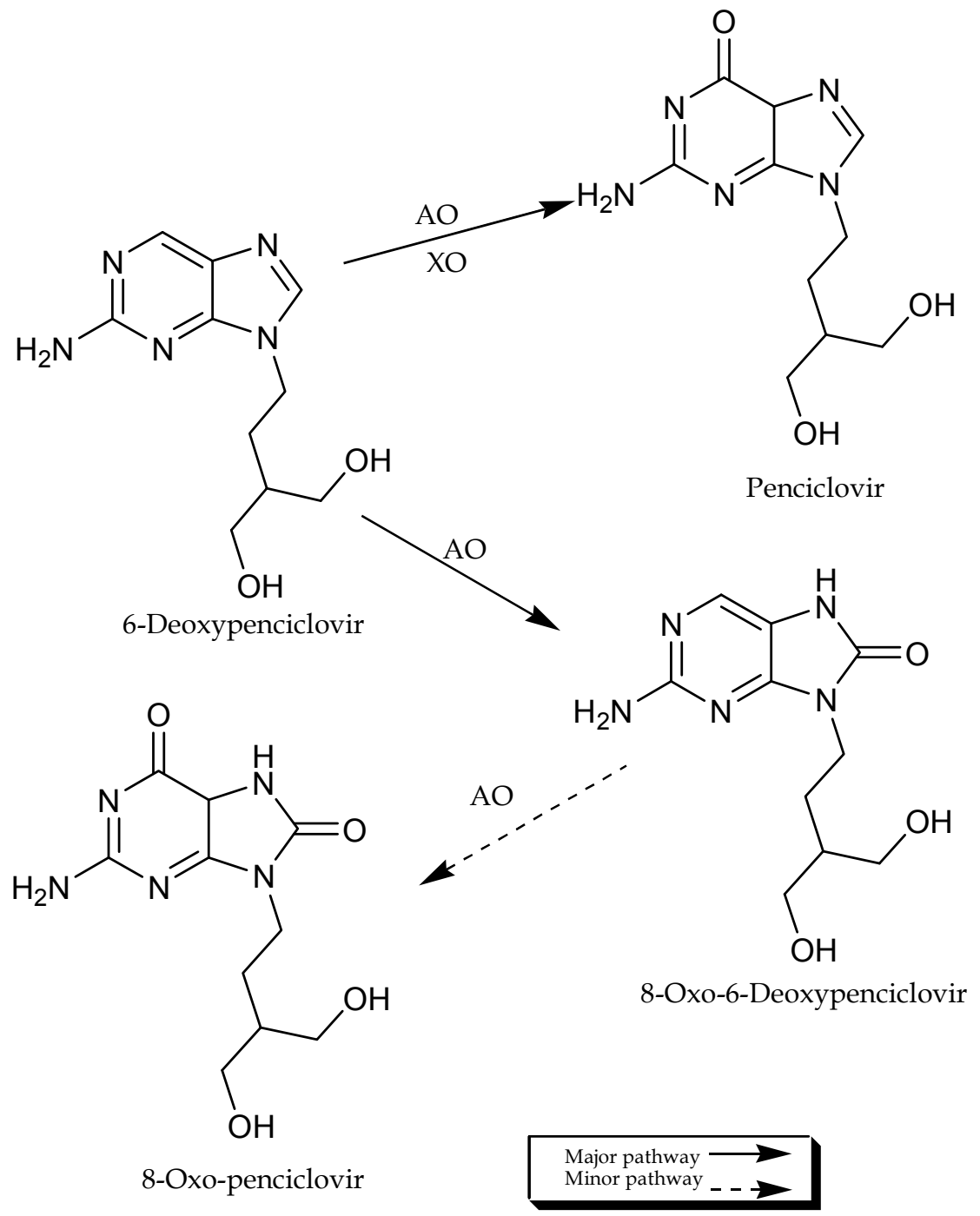

Fig. 9. The oxidative metabolic pathways of 6-deoxypenciclovir catalyzed by partially purified rabbit liver fractions (Rashidi, 1996; Rashidi et al., 1997). AO: aldehyde oxidase, XO: xanthine oxidase 


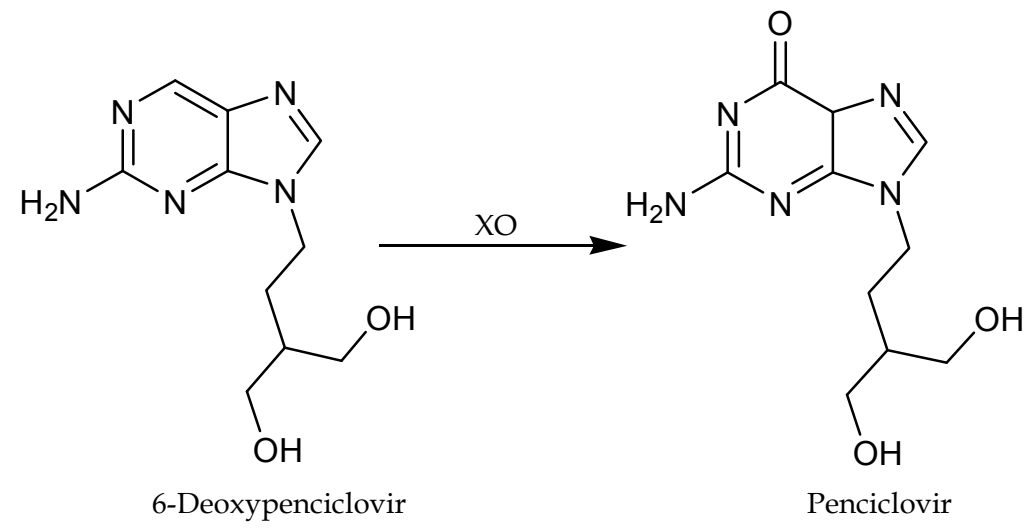

Fig. 10. The oxidative metabolic pathways of 6-deoxypenciclovir catalyzed by partially purified aldehyde oxidase-deficient rat liver fractions (Rashidi, 1996). XO: xanthine oxidase

\subsection{Ganciclovir}

Ganciclovir is an acyclic nucleoside analog of 2'-deoxyguanosine from which the 2 ' carbon has been deleted. It is used for the treatment of cytomegalovirus (CMV) infections, most commonly retinitis, colitis, and esophagitis, in immunocompromised patients and is administered to transplant patients at risk for CMV retinitis (Mondal, 2008; Physician's Desk Reference, 2000).

Ganciclovir is much more effective than aciclovir against CMV and HSV (De Clercq \& Field, 2006; Noble \& Faulds, 1998), although it has greater potential toxicity (Crumpacker, 1996). It is more easily phosphorylated in CMV infected cells than aciclovir and its triphosphate has a 5-fold higher affinity for CMV DNA polymerase than aciclovir triphosphate (KrogsgaardLarsen, 1992). Ganciclovir is also active against VZV and EBV; however, it causes neutropenia and its clinical use is restricted to the treatment of CMV infections in immunocompromised patients (Krogsgaard-Larsen, 1992).

Like aciclovir, the absorption of ganciclovir following oral administration is low. Its absolute bioavailability after oral administration of $1000 \mathrm{mg}$ of ganciclovir capsules three times a day was approximately 8.5\% (Anderson et al., 1995). To overcome this problem, in accordance with the prodrug approaches, various analogues of ganciclovir were synthesized. One of the strategies used was the synthesis of C-6 deoxy 2-aminopurine prodrugs of ganciclovir. Significant success with this strategy had been achieved previously by aciclovir. The dipivalate ester of 6-deoxyganciclovir was one of the prodrugs of ganciclovir that was produced using this strategy (Krasny et al., 1995). The dipivalate ester was introduced to increase lipophilicity of the molecule. Because of chemical similarity of aciclovir and ganciclovir, it was also expected that the 6-deoxy prodrug would be converted to gannciclovir. According to preclinical studies in rats, a 7 -fold enhancement in oral bioavailability of the compound was observed and the prodrug was rapidly converted to ganciclovir and 6-deoxy ganciclovir in vivo; however, the 6-deoxy ganciclovir was not oxidized to ganciclovir by $\mathrm{XO}$. Rat liver sometimes has insufficient $\mathrm{XO}$ activity and the results obtained from this animal model cannot be extrapolated to human, in particular with 
nucleobase antiviral agents (Rashidi et al., 1997). Therefore, the involvement of AO or XO in conversion of 6-deoxyganciclovir produced from its dipivalate ester analogue to ganciclovir cannot be ruled out and further studies may be required.

The other example of the use of prodrug approach to increase the oral bioavailability of ganciclovir is HOE 602, the bis-isopropyl ether of 6-deoxy ganciclovir. HOE 602 is a nucleobase analog of ganciclovir with high therapeutic efficacy against HSV and MCMV infections in mice (Winkler et al., 1990). Pharmacokinetic studies in mice and rhesus monkeys indicated that this prodrug is converted to ganciclovir via a three-step pathway (Fig. 11) and yields a 4 to 21-fold increase in exposure after oral administration in monkeys compared to an equivalent oral dose of ganciclovir (Winkler et al., 1990). The first step, oxidation of the 6-aminopurine moiety to guanine, is mediated by XO (Winkler et al., 1990). However, no further studies of HOE 602 have been published (Li et al., 2008).<smiles>CCOCC(COC(C)C)OCn1cnc2c(=O)[nH]cnc21</smiles>

Fig. 11. Conversion of HOE 602 prodrug to ganciclovir (Winkler et al., 1990). XO: xanthine oxidase

Valganciclovir, a valine ester of ganciclovir, is another example of prodrug approach to overcome the poor oral absorption of ganciclovir (Maag, 2002). Following oral administration of valganciclovir in human, the absolute bioavailability of ganciclovir could be 10-fold higher than that from oral ganciclovir (Jung \& Dorr, 1999; Pescovitz et al., 2000). According to these studies, no significant amount of the prodrug was detected in plasma which may be indicative of rapid and complete hydrolysis of valganciclovir to ganciclovir in vivo (Li et al., 2008). 


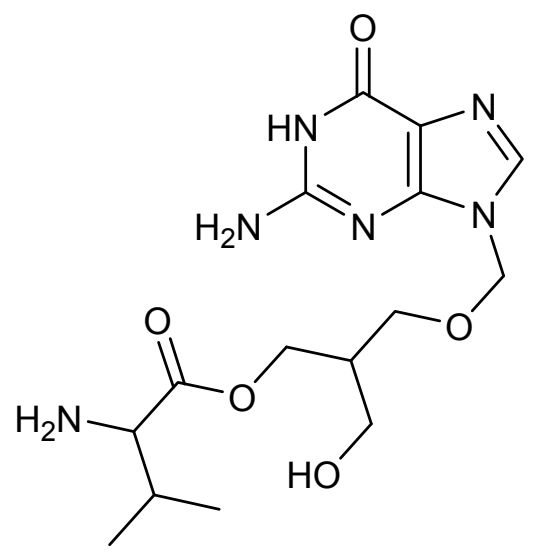

Valganciclovir

Conversion of valganciclovir to ganciclovir is a hydrolytic reaction and therefore is not dependent to molybdenum hydroxylases. However, C-8 carbon in both valganciclovir and ganciclovir, like other purine-based antiviral agents such as 6-deoxypenciclovir and aciclovir, is susceptible for oxidation by these oxidative enzymes which is subject for further studies. Interestingly, according to Krasny et al. (1995), after oral administration of dipivalate ester of 6-deoxyganciclovir to cynomolgus monkey, but not rat, the 8-hydroxy analogs of ganciclovir and 6-doxyganciclovir are also detected alongside of other metabolites.

\subsection{Aciclovir and valaciclovir}

Acyclovir, 9-[(2-hydroxy ethoxy) methyl] guanine is a guanosine analogue antiviral agent that has a high therapeutic index. It was the first specific antiviral drug described in the early 1980s (Dollery, 1999) and then the spectrum compound of the first aciclovir were boarded to vital therapies for DNA virus and retrovirus infections (Field \& De Clercq 2004; De Clercq \& Holy, 2005). Aciclovir is initially phosphorylated to a monophosphate derivative by a virus-specific thymidine kinase, and not by the thymidine kinase of uninfected cells (Rajalakshmi et al., 2010) and then to a triphosphate which inhibits competitively DNA synthesis in the infected cells. Phosphorylation does not occur in healthy cells which accounts for its strong selectivity of action (Clercq \& Holy, 2005). Consequently, the amount of aciclovir triphosphate formed in the virally infected cells is 40100 times greater than that in normal uninfected cells (Rajalakshmi et al., 2010). Aciclovir is a potent and selective inhibitor of herpes virus DNA replication. It acts as a substrate for the enzyme viral DNA polymerase in competition with normal deoxy adenosine triphosphate and results in complete and irreversible inhibition of herpes virus DNA polymerase and viral DNA chain termination (Rajalakshmi et al., 2010).

Clinically, aciclovir has been found effective against all types of HSV and VZV but not against other species of viruses (Hirsch \& Schooley, 1983). In spite of its effective antiviral activity, aciclovir has some important limitations. Firstly, it is significantly less effective 
against VZV than against HSV (Safrin \& Phan, 1993) (Easterbrook \& Wood, 1994). Furthermore, some cases of HSV and VZV isolates resistant to aciclovir have been reported(Safrin \& Phan, 1993) (Easterbrook \& Wood, 1994). In addition, aciclovir has relatively low (15-20\%) and unpredictable oral bioavilability (Easterbrook \& Wood, 1994) (de Miranda \& Blum, 1983) resulting in the need for frequent high doses or intravenous therapy in conditions where high plasma aciclovir levels are necessary to inhibit less sensitive viruses as in like VZV (de Miranda \& Burnette, 1994; Safrin \& Phan, 1993).

Consequently, many attempts have been made to improve aciclovir efficiency when given orally in humans or to find new successors to aciclovir. Development of a prodrug of aciclovir with a better absorption from the gastrointestinal tract and then conversion in vivo to aciclovir has been one of the most common strategies used to achieve this goal (Burnette, T.C. \& de Miranda 1994; Hay CM, Reichman 2008; Krenitsky et al., 1984).

One such prodrug is 6-deoxyaciclovir or desciclovir, 2-amino-9-[2-hydroxyethoxy) methyl]9H-purine. 6-Deoxyciclovir is an analog of aciclovir which is 18 times more water soluble than aciclovir (Krenitsky et al., 1984). The prodrug is extensively absorbed following oral administration to healthy volunteers and converted to aciclovir in vivo by the $\mathrm{XO}$; however, XO cannot further oxidize aciclovir (Fig. 12) (Krenitsky et al., 1984). On the other hand, aciclovir is hydroxylated at $\mathrm{C}-8$ by $\mathrm{AO}$, but this enzymatic reaction is a minor metabolic pathway in patients (Beedham, 1997).

Although 6-deoxyaciclovir has been reported as XO-activated prodrugs (Krenitsky et al., 1984; Jones et al., 1987), the compound is a better substrate for AO than XO (Table 2). Like 6deoxypenciclovir, 6-deoxyaciclovir is oxidized to 8-oxo-metabolite as the major metabolite by rabbit liver $\mathrm{AO}$ (Fig. 13) and its $\mathrm{Vmax} / \mathrm{Km}$ value is 57 -fold higher than that of BMXO (Krenitsky et al., 1984). It has been reported that allopurinol was less effective in inhibition of 6-deoxyaciclovir oxidation to aciclovir in isolated perfused Sprague-Dawley rat livers (Jones et al., 1987) whose liver AO is very variable. The ratio of 8-oxo-metabolite to 6-oxometabolite (aciclovir) from the oxidation of 6-deoxyaciclovir by rabbit liver $\mathrm{AO}$ is 95 to 5 (Krenitsky et al., 1984). Although the bioavailability of 6-deoxyaciclovir was improved, further development of the prodrug was terminated due to the chronic toxicity problems highlighted in animal studies (de Miranda P \& Burnette, 1994).

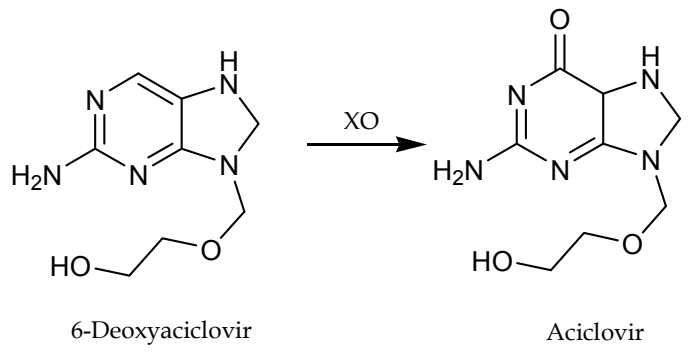

Fig. 12. 6-Deoxyaciclovir as a prodrug of aciclovir is activated by xanthine oxidase (XO) (Krenitsky et al., 1984) 


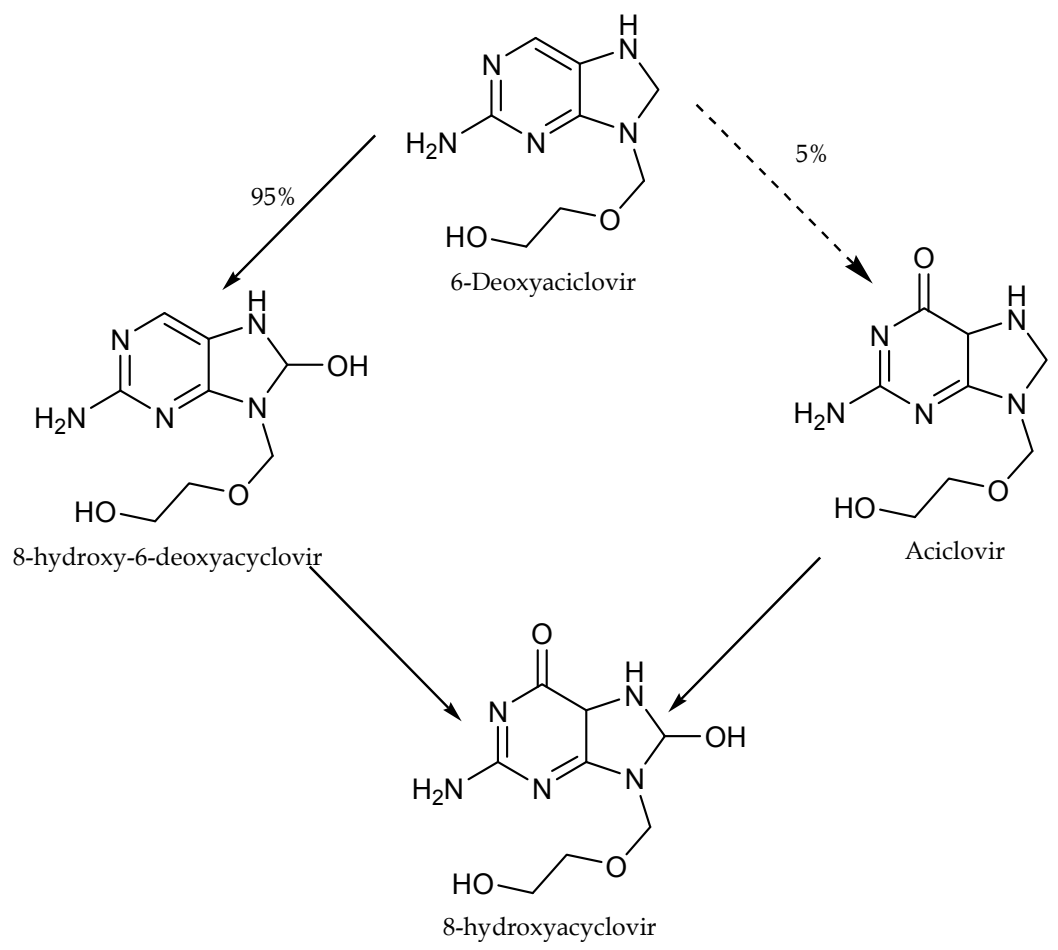

Fig. 13. Metabolism and inactivation of 6-deoxyaciclovir by rabbit liver aldehyde oxidase (Krenitsky et al., 1984)

AO converts 6- Deoxyaciclovir to 8-hydroxy-6-deoxyaciclovir and aciclovir with the ratio of 95 to 5 respectively, and both of them are turned more oxidase to 8-hydroxyaiclovir (Krenitsky et al., 1984).

Valaciclovir, 2-[2-amino-1， 6-dihydro-6-oxo-9H-purin-9-yl-methoxy] ethyl valinate hydrochloride, is another oral prodrug of aciclovir with an oral bioavailibility of higher than that of acyclovir (Burnette, T.C. \& de Miranda 1994; Hay CM \& Reichman, 2008). Valaciclovir is well absorbed following oral administration and is rapidly converted to aciclovir by hydrolysis of the valyl ester during first pass intestinal and/or hepatic metabolism (Burnette, T.C. \& de Miranda, 1994; de Miranda, P. \& Burnette, 1994). Therefore, the mechanism of action and spectrum of activity of valaciclovir are the same as that of acyclovir (Rajalakshmi et al., 2010).

\subsection{Carbovir}

Carbovir is a carbocyclic guanosine derivative with a potent and selective inhibitory effect on HIV-1 replication (Vince et al., 1988). As its oral bioavailability is low (Huang et al., 1991), its prodrug, 6-deoxycarbovir was synthesized in attempt to increase its oral absorption. The chemical structure of 6-deoxycarbovir is very similar to that of 6-deoxypenciclovir and 6deoxyaciclovir. Like 6-deoxyaciclovir, 6-deoxycarbovir has been reported as $\mathrm{XO}$-activated 
prodrug (Vince et al., 1995), but it is also a better substrate for AO than XO (Table 2). 6Deoxycarbovir is oxidized at C-8 position and 8-hydroxy-6-deoxycarbovir is the main metabolite produced from incubation of 6-deoxycarbovir with rabbit liver $\mathrm{AO}$, but with guinea pig liver $\mathrm{AO}$, 6-hydroxylation is the major metabolic pathway and carbovir is produced as almost the only oxidative metabolite.

8-Hydroxy-6-deoxyaciclovir lacks appreciable activity against herpes simplex type I in vitro (Krenitsky et al., 1984). As substitution at carbon 8 generally results in loss of antiviral activity (Beedham, 1997), 8-hydrox-6-deoxycarbovir is expected to be dvoid of antiviral activity. It is likely that $\mathrm{AO}$ from other sources like guinea pig liver, which is a better animal model for human liver AO (Rashidi, 1996), acts as the main enzyme in oxidative conversion of 6-deoxyaciclovir to aciclovir as it is the case with 6-deoxypenciclovir and 6deoxycarbovir. The assay of 6-deoxyaciclovir oxidation by hepatic AO from species such as guinea pig and human and pharmacokinetics of 6-deoxyaciclovir following administration of the compound should be subject to further studies.

\begin{tabular}{|c|c|c|c|c|c|c|}
\hline \multirow[b]{2}{*}{$\begin{array}{l}\text { Enzyme } \\
\text { fraction }\end{array}$} & \multicolumn{2}{|c|}{ 6-Deoxypenciclovir } & \multicolumn{2}{|c|}{ 6-Deoxycarbovir } & \multicolumn{2}{|c|}{ 6-Deoxyaciclovir } \\
\hline & $\begin{array}{l}\mathrm{Km} \\
(\mathrm{mM})\end{array}$ & $\begin{array}{l}\text { 6-oxo-metabolite } \\
\text { / } \\
\text { 8-oxo-metabolite }\end{array}$ & $\begin{array}{l}\mathrm{Km} \\
(\mathrm{mM})\end{array}$ & $\begin{array}{l}\text { 6-oxo-metabolite } \\
\text { / } \\
\text { 8-oxo-metabolite }\end{array}$ & $\begin{array}{l}\mathrm{Km} \\
(\mathrm{mM})\end{array}$ & $\begin{array}{l}\text { 6-oxo-metabolite } \\
\text { / } \\
\text { 8-oxo-metabolite }\end{array}$ \\
\hline Guinea pig & 0.41 & 27 & 0.40 & 100 & ND & ND \\
\hline Rabbit & 0.44 & 0.9 & 0.11 & 0.3 & 0.06 & 0.05 \\
\hline Rat liver XO & 0.26 & a & 0.22 & a & ND & ND \\
\hline ВМХO & 0.90 & a & ND & ND & 0.9 & $\mathrm{a}$ \\
\hline
\end{tabular}

a: 6-Oxo-metabolite was the only metabolite produced.

ND: Not determined

Table 2. The Km value for the formation of 6-oxo-metabolite and the ratio of 6-oxo- to 8-oxometabolite for the oxidation of 6-deoxypenciclovir, 6-deoxycarbovir and 6-deoxyaciclovir catalyzed by guinea pig, rabbit, rat liver xanthine oxidase $(\mathrm{XO})$ and bovine milk xanthine oxidase (BMXO) (Krenitsky et al., 1984; Rashidi 1996; Rashidi et al., 1997).

\subsection{Vidarabine}

Vidarabine (9- $\beta$-D-Arabinosyladenine, adenine arabinoside, Ara-A, Vira-A), a marinederived drug has been shown to have antitumor activity. However, it has become more notable for its antiviral activity with a high therapeutic index (Hansel et al., 2004; Hirsch \& Schooley, 1983). In the 1964, the first study on the antiviral activity of vidarabine was explained by Private de Grilhe and De Rudder (Private de Grilhe \& De Rudder, 1964). Following, Whiley described vidarabine activity in the treatment of herpes encephalitis and the other herpes infection in newborns (Field \& De Clerq, 2004). Vidarabine possess significant activity against infections caused by herpes viruses, pox viruses, rhabdoviruses, 
hepadnaviruses, the vaccinia virus, VZV, and some RNA tumor viruses. Although vidarabine is supplanted by acyclovir and other analogs for most applications, it is still used as an alternative therapy for acyclovir-resistant HSV and VZV infections (Gentry et al., 2008).

However, vidarabine is extensively deaminated in the body by adenosine deaminase (ADA) to 9- $\beta$-D-arabinofuranosylhypoxanthine (hypoxanthine arabinoside) that has less antiviral activity than vidarabine, which is a major limitation in its clinical use (Shen et al., 2009; Shope et al., 1983; Sloan et al., 1977). Inhibition of ADA by co-administration of modified purine analogues with vidarabine, such as deoxycoformacine, can improve the therapeutic effect of vidarabine (Bryson et al., 1974, 1976). In addition, vidarabine has limited lipid solubility which the low delivery from cell membrane and very low solubility in water (about $0.47 \mathrm{mg} / \mathrm{ml}$ ), therefore, the large fluid volumes is needed for intravenous administration (Baker et al., 1978; Hirsch \& Schooley, 1983; Whitley et al., 1980).

Vidarabine is a nucleoside analog; therefore, it has to be phosphorylated and to be active. It is phosphorylated to its monophosphate, $\mathrm{di}$ - and triphosphate nucleotides which during the synthetic (S) phase inhibit DNA polymerase and strongly in the virus such as herpes, vaccinia and varicella zoster viruses than in the host cells (Dicioccio \& Srivastava, 1977; Doering et al., 1966; Rose \& Jacob, 1978; Shipman et al., 1976). As well, vidarabine is integrated into RNA in virus and inhibit RNA polyadenylation reaction (Rose \& Jacob, 1978).

In mammalian cell, vidarabine is rapidly converted by ADA to hypoxanthine arabinoside which has less antiviral activity than vidarabine. Hypoxanthine arabinoside is the major metabolite of vidarabine is excreted renally and biotransformed by $\mathrm{XO}$ to xanthine arabinoside (Fig. 14) (Connor et al., 1975; Friedman \& Grasela, 1981; Hirsch \& Schooley, 1983; Shen et al., 2009). Allopurinol as an inhibitor of XO can interfere with the metabolism of vidarabine and, therefore, co-administration of allopurinol with vidarabine should be avoided or used with caution (Woster, 2007). The role of AO in this metabolic pathway, in particular oxidation of xanthine arabinoside at $C-8$, has not been investigated and could be a subject for future studies.

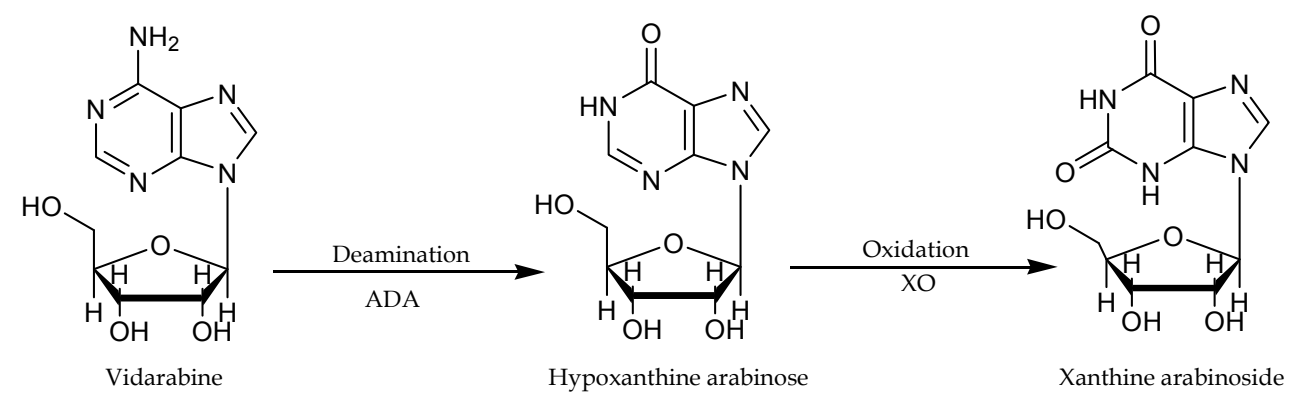

Fig. 14. The biotransformation of vidarabine in mammalian cells. Vidarabine is converted to hypoxanthine arabinoside through deamination by adenosine deaminase (ADA), followed by oxidation to xanthine arabinoside by xanthine oxidase (XO) (Connor et al., 1975;

Friedman \& Grasela, 1981; Gannon et al., 1984; Shen et al., 2009). 


\subsection{Theophylline}

Theophylline (1,3-dimethylxanthine) is a methylxanthine which is widely distributed in nature. It is widely used as a bronchodilator agent for the treatment of various asthmatic and pulmonary conditions under a variety of brand names and is one of the most widely prescribed drugs for the treatment of airway diseases worldwide (Barnes, 2003). Theophylline acts as an effective drug in clinical trials against air way narrowing and prevents wheezing, cough, shortness of breath and difficulty breathing which is caused by asthma and different lung disease. It is also helpful in patient with chronic obstructive pulmonary disease (COPD) including chronic bronchitis and emphysema which opens air way lung to make breach easer (Aronson et al., 1992; Pauwel, 1987; Vielhaber \& Kavuru, 2001).

Theophylline is metabolized in the human liver through $\mathrm{N}-1$ or N-3 demethylation followed by hydroxylation at C-8 producing three main products including 3-methylxanthine (3MX), 1-methyluric acid (1MU) and 1,3-dimethyluric acid (1,3DMU) (Fig. 15) (Brikett et al., 1983; Lu et al., 2003; Yao et al., 2001). It is thought that cytochrome P450 1A2 (CYP1A2) is the most important enzyme involved in the catalysis of these reactions (HR et al., 1995; Tjia et al., 1996). Cytochrome P450 2E1 (CYP2E1) can also mediate C-8 hydroxylation but its contribution in this reaction is low (HR et al., 1995; Tjia et al., 1996).

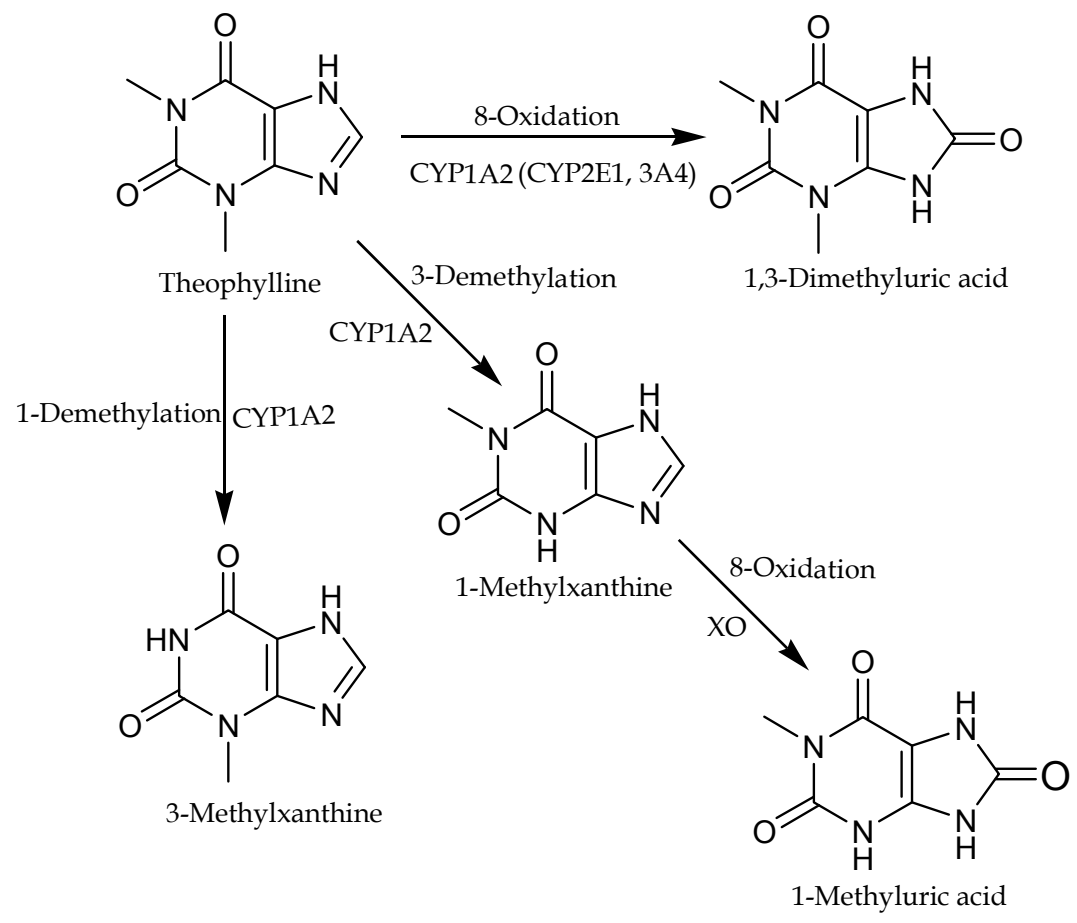

Fig. 15. The biotransformation of theophylline through CYP450 family and xanthine oxidase (Brikett et al., 1983; HR et al 1995; Lu et al., 2003; Tjia, et al 1996; Yao et al., 2001). CYP1A2: Cytochrome P450 1A2, CYP2E1: Cytochrome P450 2E1, XO: Xanthine Oxidase 
1-Methyluric acid is the secondary metabolic pathway of theophylline. It is produced following a rapid oxidation from 1-methylxanthin by XO (Fig. 15) (Brikett et al., 1983). In contrast to the other methylxanthines, 1-methylxanthin is a good substrate for XO (Bergmann \& Dikstein, 1956; Krenitsky et al., 1972; Lohmann \& Miech, 1976) and used as a XO activity index for plasma concentration of oxypurinal in man (Graham et al., 1996). The involvement of $\mathrm{XO}$ in the metabolism of theophylline has also been used for the construction of amperometric enzyme electrodes to quantitative measurement of theophylline (Stredansky et al., 2000). Allopurinal as a potent inhibitor of XO activity decreases the formation of 1-methyleuric acid from the 1-methylxanthine in theophylline oxidation (Brikett et al., 1983; German DC, 1986).

\section{Conclusion}

Drug metabolism is one of the important factors that may play a major role in drug development and toxicity. $\mathrm{AO}$ and $\mathrm{XO}$ are two molybdenum-containing enzymes that are involved in the metabolism of an extensive range of aldehydes and N-heterocyclic aromatic compounds (Beedham, 1997; Rashidi \& Nazemiyeh, 2010). Although the importance of molybdenum hydroxylases in drug metabolism has usually been overshadowed by that of CYP450 as the most important drug metabolizing enzyme system, we will witness a significant increase in the importance of $\mathrm{XO}$ and $\mathrm{AO}$ in drug metabolism over the next decade (Alfaro et al 2009; Obach et al., 2004). Purines as $\mathrm{N}$-heterocyclic compounds, thus, can serve as substrate for $\mathrm{AO}$ and $\mathrm{XO}$ and the importance of molybdenum hydroxylases in the metabolism of purines and also the development of purine related prodrugs has been demonstrated by several authors (Clarke et al., 1995; Kitchen et al., 1999; Krenitsky et al., 1984; Rashidi et al., 1997, 2007; Van Scoik et al., 1985).

The reaction catalyzed by $\mathrm{AO}$ and $\mathrm{XO}$ involves a nucleophilic attack on an electron-deficient sp2-hybridized carbon atom adjacent to a ring nitrogen atom in N-heterocyclic compounds. Therefore, nitrogen-containing aromatic compounds including purines can act as appropriate substrates for $\mathrm{XO}$ and $\mathrm{AO}$. Purine nucleus contains several nitrogen atoms and is sequentially oxidized at three different positions; in a substituted purine analogue, any of these sites could be attacked by $\mathrm{AO}$ and $\mathrm{XO}$ with varying affinities and/or rates (Beedham, 2010).

On the other hand, significant interspecies variations exist in both the number and activity of both AO and XO, in particular the former enzyme (Alfaro et al., 2009; Jones et al., 1987; Krenitsky et al., 1984; Rashidi et al., 1997). Therefore, not only it is difficult to predict which metabolite will be produced from a purine-based drug by $\mathrm{AO}$ or $\mathrm{XO}$, but also it would be a hard task to recognize which of these two enzymes has a dominant contribution in the metabolic pathway. In addition, it would be difficult to find a suitable animal model and extrapolate the results obtained from the animal studies to man.

As it was shown in the previous sections, there are several purine related drugs or prodrugs that are metabolized by $\mathrm{AO}$ and/or $\mathrm{XO}$; however, the manner of the oxidation sites could be completely different for these two enzymes. For example, famciclovir and 6- 
deoxycarbovir are converted to their corresponding active agent by $\mathrm{AO}$ with purine oxidation occurs at carbon 6 . But, rabbit liver enzyme acts differently and attacks mainly at carbon 8 of the purine nucleus. In contrast to $\mathrm{AO}, \mathrm{XO}$ has a little contribution to the activation of these purine analogues. Not surprisingly, Krenitsky et al. (Krenitsky et al., 1972,1984) has shown that the oxidation occurs at carbons 6 and 8 with XO and rabbit liver AO, respectively. 6-Deoxyaciclovir which is also a purine-based prodrug is oxidized at the 6-position by $\mathrm{XO}$, whereas rabbit enzyme oxidizes 6-deoxyaciclovir to 8-oxo-6deoxyaciclovir (Krenitsky et al., 1984). However, it has been found that (Iyer, 1992; Rashidi et al., 1997) rabbit liver AO differs to the enzyme from other species in oxidizing carbon 8 of $2-\mathrm{NH}_{2}-9$-substituted purines instead of the 6-position. Therefore, it is more likely that 6-deoxyaciclovir is predominantly oxidized to aciclovir by AO from human, guinea pig or rat livers which are subject for further studies. This could be case for other purine related drugs that their metabolism has been attributed to XO. Conducting comparative studies, the like of which has been carried out with famciclovir (Rashidi et al., 1997), would be of great value in elucidating the contribution of $\mathrm{AO}$ and XO in the metabolism of these purine-based agents. In these studies, the selection of an appropriate animal model for human AO would be a problem because of the different substrate specificity of enzyme from each species.

\section{References}

Alfaro, J.F.; Joswig-Jones, C.A.; Ouyang, W.; Nichols, J.; Crouch, G.J.; \& Jones, J.P. (2009). Purification and mechanism of human aldehyde oxidase expressed in Escherichia coli. Drug Metab Dispos, 37(12): 2393-2398.

Anderson, R.D.; Griffy, K.G.; Jung, D.; Dorr, A.; Hulse, J.D.; \& Smith, R.B. (1995). Ganciclovir absolute bioavailability and steady-state pharmacokinetics after oral administration of two 3000-mg/d dosing regimens in human immunodeficiency virus- and cytomegalovirus-seropositive patients. Clin Ther, 17(3):425-432.

Ansari, A.; Aslam, Z.; De Sica, A.; Smith, M.; Gilshenan, K.; Fairbanks, L.; Marinaki, A.; Sanderson, J.; \& Duley, J. (2008). Influence of xanthine oxidase on thiopurine metabolism in Crohn's disease. Aliment Pharmacol Ther, 28(6):749-757.

Aronson. J.K.; Hardman, M.; Reynolds D.J. (1992). "ABC of monitoring drug therapy. Theophylline." BMJ, 305(6865):1355-1358.

Baker, D.C.; Haskell, T.H.; \& Putt, S.R. (1978). Prodrugs of 9-beta-Darabinofuranosyladenine. 1. Synthesis and evaluation of some 5'-(O-acyl) derivatives. J Med Chem, 21(12): 1218-1221.

Beedham, C. (1997). The role of non-P450 enzymes in drug oxidation, Pharm World Sci, 19(6):255-263.

Beedham, C. (2010). Xanthine Oxidoreductase and Aldehyde Oxidase, Comprehensive Toxicology, Chapter 4.10, 185-205.

Beedham, C. (2002). Molybdenum hydroxylase, In: Enzyme systems that methabolize drugs and other xenobiotics, C. Ioannides (Ed.), John Wiley \& Sons Ltd., pp 147-187. 
Bergmann, F.; \& Dikstein, S. (1956). Studies on uric acid and related compounds. III. Observations on the specificity of mammalian xanthine oxidases. J Biol Chem, 223(2):765-780.

Birkett, D.J.; Miners, J.O.; \& Attwood, J. (1983). Secondary metabolism of theophylline biotransformation products in man--route of formation of 1-methyluric acid. Br J Clin Pharmacol, 15(1): 117-119.

Bryson, Y.; Connor, J.D.; Sweetman, L.; Carey, S.; Stuckey, M.A.; Buchanan, R. (1974). Determination of plaque inhibitory activity of adenine arabinoside (9-beta-Darabinofuranosyladenine) for herpesviruses using an adenosine deaminase inhibitor. Antimicrob Agents Chemother, 6(1): 98-101.

Bryson, Y.J.; \& Connor, J.D. (1976). In vitro susceptibility of varicella zoster virus to adenine arabinoside and hypoxanthine arabinoside. Antimicrob Agents Chemother, 9(3): 540543.

Burnette, T.C.; \& de Miranda, P. (1994). Metabolic disposition of the acyclovir prodrug valaciclovir in the rat. Drug Metab Dispos, 22(1):60-64.

Chalmers, A.H.; Knight, P.R.; \& Atkinson, M.R. (1969). 6-thiopurines as substrates and inhibitors of purine oxidases: a pathway for conversion of azathioprine into 6thiouric acid without release of 6-mercaptopurine. Aust J Exp Biol Med Sci, 47(2):263-273.

Clarke, S.E.; Harrell, A.W.; \& Chenery, R.J. (1995). Role of aldehyde oxidase in the in vitro conversion of famciclovir to penciclovir in human liver. Drug Metab Dispos, 23(2):251-254.

Chabner, B.A.; Ryan, B.P.; Paz-Ares, L.; Garcia-Carbonero, R.; \& Calabresi, P. (2001). Antineoplastic Agents. In Goodman and Gilman's The Pharmacological Basis of Therapeutics, 10th ed. J.G.; Hardman, L.E.; Limbird, A.; Gilman, (Eds.), New York: McGraw-Hill. pp. 1389-1459.

Connor, J.D.; Sweetman, L.; Carey, S.; Stuckey, M.A.; \& Buchanan, R. (1975). Susceptibility in vitro of several large DNA viruses to the antiviral activity of adenine arabinoside and its metabolite, hypoxanthine arabinoside: relation to human pharmacology. In: Adenine arabinoside: an antiviral agent. D.; Pavan-Langston, R.A.; Buchanan, C.A.; Alford, (Eds.), New York: Raven Press, 177-196.

Crumpacker, C.S. (1996). Ganciclovir. N Engl J Med, 335(10):721-729.

De Clercq, E.; \& Field, H.J. (2006). Antiviral prodrugs-the development of successful prodrug strategies for antiviral chemotherapy. Br J Pharmacol, 147(1):1-11.

Di Iorio, P.; Ballerini, P.; Caciagli, F.; \& Ciccarelli, R. (1998). Purinoceptor-mediated modulation of purine and neurotransmitter release from nervous tissue. Pharmacol Res, 37(3):169-178.

De Clercq, E.; \& Holy, A. (2005). Acyclic nucleoside phosphonates: a key class of antiviral drugs. Nat Re Drug Discov, 4(11): 928-940.

De Miranda, P.; \& Blum, M.R. (1983). Pharmacokinetics of acyclovir after intravenous and oral administration. J Antimicrob Chemother, 12 Suppl B:29-37.

De Miranda, P.; \& Burnette, T.C. (1994). Metabolic fate and pharmacokinetics of the acyclovir prodrug valaciclovir in cynomolgus monkeys. Drug Metab Dispos, 22(1): 55-59. 
Dicioccio, R.A.; \& Srivastava, B.I. (1977). Kinetics of inhibition of deoxynucleotidepolymerizing enzyme activities from normal and leukemic human cells by 9-betaD-arabinofuranosyladenine 5'-triphosphate and 1-beta-D-arabinofuranosylcytosine 5'-triphosphate. Eur J Biochem, 79(2): 411-418.

Dollery, C. (1999). Therapeutic drugs. 2nd ed. Edinburgh: Churchill Livingstone; p. A39A44.

Doering, A.; Keller, J.; \& Cohen, S.S. (1966). Some effects of D-arabinosyl nucleosides on polymer syntheses in mouse fibroblasts. Cancer Res, 26(12): 2444-2450.

Easterbrook, P.; \& Wood, M.J. (1994). Successors to acyclovir. J Antimicrob Chemother, 34(3): 307-311.

Elion, G.B. (1967). Symposium on immunosuppressive drugs. Biochemistry and pharmacology of purine analogues. Fed Proc, 26(3): 898-904.

Elion, G.B.; Burgi, E.; \& Hitchings,G.H. (1952). Studies on Condensed Pyrimidine Systems. IX. The Synthesis of Some 6-Substituted Purines. J Am Chem Soc, 74:411-414.

Elion, G.B.; Hitchings G.H.; \& Vander Werff, H. (1951). Antagonists of nucleic acid derivatives. VI. Purines. J Biol Chem, 192(2): 505-518.

Evans, W.E.; \& Relling, M.V. (1994). Mercaptopurine vs thioguanine for the treatment of acute leukemia. Leuk Res, 18(11): 811-814.

Field, H.; \& De Clercq, E. (2004). Antiviral drugs-a short history of their discovery and development. Microbiol Today, 31,58-61.

Fotoohi, A.K.; Coulthard, S.A.; \& Albertioni, F. (2010). Thiopurines: factors influencing toxicity and response. Biochem Pharmacol, 79(9):1211-1220.

Friedman, H.M. (1981). Adenine arabinoside and allopurinol--possible adverse drug interaction. N Engl J Med, 304(7):423.

Gentry, B.G.; Shen, W.; Breitenbach, J.M.; Hilfinger, J.; \& Drach, J.C. (2008). Vidarabine Prodrugs as Potential Inhibitors of Adenosine Deaminase. Antiviral Res, 78(2): A56.

German, D.C.; \& Holmes, E.W. (1986). Hyperuricaemia and gout. Med Clinics of North Am, 70: 419-436.

Hall, W.W.; \& Krenitsky, T.A. (1986). Aldehyde oxidase from rabbit liver: specificity toward purines and their analogs. Arch Biochem Biophys, 251(1):36-46.

Hande, K.R.; \& Garrow, G.C. (1996). Purine antimetabolites. In: Cancer Chemotherapy and Biotherapy: Principles and Practice, B.A; Chabner, \& D.L. Longo, (Eds.), LippincottRaven Publishers, Philadelphia, pp 235-252.

Graham, S.; Day, R.O.; Wong, H.; McLachlan, A.J.; Bergendal, L.; Miners, J.O.; \& Birkett, D.J. (1996). Pharmacodynamics of oxypurinol after administration of allopurinol to healthy subjects. Br J Clin Pharmacol, 41(4):299-304.

Hansel, T.T.; Tennant, R.C.; Tan, A.J.; Higgins, L.A.; Neighbour, H.; Erin, E.M.; \& Barnes, P.J. (2004). Theophylline: mechanism of action and use in asthma and chronic obstructive pulmonary disease. Drugs Today (Barc), 40(1): 55-69.

Harrell, A.W.; Wheeler, S.M.; Pennick, M.; Clarke, S.; \& Chenery, R.J. (1993). Evidence that famciclovir (BRL 42810) and its associated metabolites do not inhibit the 6 betahydroxylation of testosterone in human liver microsomes. Drug Metab Dispos, 21(1):18-23. 
Hay, C.M.; \& Reichman, R.C. (2008). Antiviral Drugs. In: Fitzpatrick`s Dermatology in General Medicine. K.; Wolff, L.A.; Goldsmith, S.I.; Katz, B.A.; Gilchrest, A.S.; Paller, D.J.; \& Leffel, (Eds.), 7th ed. New York: McGraw-Hill; P. 2203-2211.

Hirsch, M. S. and R. T. Schooley (1983). Drug therapy. Treatment of herpesvirus infections. N Engl J Med, 309(16):963-970.

Huang, S.H.; Remmel, R.P.; \& Zimmerrman, C.L. (1991). The bioavailability and nonlinear clearance of (-)-carbovir in the rat. Pharm Res, 8:739-743.

Hirsch, M.S.; \& Schooley, R.T. (1983). Drug therapy. Treatment of herpesvirus infections. N Engl J Med, 309(16):963-970.

Hitchings, G.H. (1978). Uric acid: chemistry and synthesis. In: Uric Acid, W.N.; Kelley, \& I.M.; Weiner (Eds.), Berlin, Heidelberg and New York, Springer-Verlag, pp:1-20. Berlin, Heidelberg, pp. 1-20. ISBN: 3540086110, 9783540086116.New York.

Hurst, D.T. (1980). An Introduction to the Chemistry and Biochemistry of Pyrimidines, Purines and Pteridines, John Wiley \& Sons.

Hogarth, L.A.; Redfern, C.P.; Teodoridis, J.M.; Hall, A.G.; Anderson, H.; Case, M.C.; \& Coulthard, S.A. (2008). The effect of thiopurine drugs on DNA methylation in relation to TPMT expression. Biochem Pharmacol, 76(8):1024-1035.

Iyer, K.R. (1992). Evaluation and metabolism of (-)-6-deoxycarbovir as a prodrug for (-)- carbovir. Dissertation Abst Inter, 53:1313-B.

Jones, D.B., Rustgi V.K., Kornhauser D.M., Woods A., Quinn R., Hoofnagle J.H., \& Jones A. (1987). The disposition of 6-deoxyacyclovir: a xanthine oxidase-activated prodrug of acyclovir in the isolated perfused rat liver. Hepatology, 7:345-348.

Joule, J.A., Mills, K.; \& Smith, G.F. (1995). Heterocyclic Chemistry, 3th Edition, Chapman \& Hall, pp. 409-433.

Jung, D.; \& Dorr, A. (1999). Single-dose pharmacokinetics of valganciclovir in HIV- and CMV seropositive subjects. J Clin Pharmacol, 39(8):800-804.

Keuzenkamp-Jansen, C.W.; van Baal, J.M.; De Abreu, R.A.; de Jong, J.G.; Zuiderent, R.; \& Trijbels, J.M. (1996). Detection and identification of 6-methylmercapto-8hydoxypurine, a major metabolite of 6-mercaptopurine, in plasma during intravenous administration. Clin Chem, 42(3):380-386.

Kitchen, B.J.; Moser, A.; Lowe, E.; Balis, F.M.; Widemann, B.; Anderson, L.; Strong, J.; Blaney, S.M.; Berg, S.L.; O'Brien, M.; \& Adamson, P.C. (1999). Thioguanine administered as a continuous intravenous infusion to pediatric patients is metabolized to the novel metabolite 8-hydroxy-thioguanine. J Pharmacol Exp Ther, 291(2):870-874.

Knoester, P.D.; Underberg, W.J.; \& Beijnen, J.H. (1993). Clinical pharmacokinetics and pharmacodynamics of anticancer agents in pediatric patients (review). Anticancer Res, 13(5C):1795-1808.

Krenitsky, T.A.; Hall, W.W.; de Miranda, P.; Beauchamp, L.M.; Schaeffer, H.J.; \& Whiteman, P.D. (1984). 6-Deoxyacyclovir: a xanthine oxidase-activated prodrug of acyclovir. Proc Natl Acad Sci USA, 81(10):3209-3213.

Krenitsky, T.A.; Neil, S.M.; Elion, G.B.; \& Hitchings, G.H. (1972). A comparison of the specificities of xanthine oxidase and aldehyde oxidase. Arch Biochem Biophys, 150(2):585-599. 
Krenitsky, T.A.; Spector, T.; \& Hall, W.W. (1986). Xanthine oxidase from human liver: purification and characterization. Arch Biochem Biophys, 247(1):108-119.

Krogsgaard-Larsen, P. (992). A Textbook of Drug Design and Development, Harwood Academic Publishers, pp. 577-605.

Krasny, H.C.; Beauchamp, L.; Krenitsky, T.A.; \& De Miranda, P. (1995). Metabolism and pharmacokinetics of a double prodrug of ganciclovir in the rat and monkey. Drug Metab Dispos, 23:1242-1247.

Lennard, L., Hale, J.P.; \& Lilleyman, J.S. (1991). Proceedings of the BPS, 659P.

Lennard, L.; Davies, H.A.; \& Lilleyman, J.S. (1993). Is 6-thioguanine more appropriate than 6-mercaptopurine for children with acute lymphoblastic leukaemia? $\mathrm{Br}$ J Cancer, 68(1):186-190.

Li, F.; Maag, H.; \& Alfredson, T. (2008). Prodrugs of nucleoside analogues for improved oralabsorption and tissue targeting. J Pharm Sci, 97(3):1109-1134.

Lohmann, S.M.; \& Miech, R.P. (1976). Theophylline metabolism by the rat liver microsomal system. J Pharmacol Exp Ther, 196(1):213-225.

Lu, P., M. L. Schrag, Slaughter, D.E.; Raab, C.E.; Shou, M.; \& Rodrigues, A.D. (2003). Mechanism-based inhibition of human liver microsomal cytochrome P450 1A2 by zileuton, a 5-lipoxygenase inhibitor. Drug Metab Dispos, 31(11): 13521360 .

Maag, H. (2002). Ganciclovir pro-drugs: Synthesis and pre-clinical development of valganciclovir (Valcyte ${ }^{\mathrm{TM}}$ ). AAPS Annual Meeting, November 13, Toronto, Canada.

Murray, A.B. (1995). Valaciclovir: an improvement over acyclovir for the treatment of zoster. Antiviral Chem Chemother, 6, 34-38.

Mondal, D. (1995). Ganciclovir. xPharm: The Comprehensive Pharmacology Reference, 1-5.

Meerten, E., Verweij, J.; \& Schellens, J.H.M. (1995). Antineoplastic agents: drug interactions of clinical significance. Drug Safety, 12: 168-182.

Noble, S.; \& Faulds, D. (1998). Ganciclovir. An update of its use in the prevention of cytomegalovirus infection and disease in transplant recipients. Drugs, 56(1):115146.

Obase, Y.; Shimoda, T.; Kawano, T.; Saeki, S.; Tomari, S.Y.; Mitsuta-Izaki, K.; Matsuse, H.; Kinoshita, M.; \& Kohno, S. (2003). Polymorphisms in the CYP1A2 gene and theophylline metabolism in patients with asthma. Clin Pharmacol Ther 73(5):468-474.

Palella, T.D., \& Fox, I.H. (1991). Purine and Pyrimidine Metabolism, In: Encyclopedia of Human Biology, R.; Dulbecco, (Ed.), Vol. 6, Academic Press, pp. 387-398.

Pauwels, R. (1987). The effects of theophylline on airway inflammation. Chest, 92(1 Suppl): 32S-37S.

Physician's Desk Reference 2000. Physicians' Desk Reference, Edition 54. , Medical Economics company, Montvale, New Jersey.

Perry, C.M., \& Wagstaff, A.J. (1995). Famciclovir. A review of its pharmacological properties and therapeutic efficacy in herpesvirus infections. Drugs 50(2):396-415.

Pescovitz, M.D., Rabkin, J.; Merion, R.M.; Paya, C.V.; Pirsch, J.; Freeman, R.B.; O'Grady, J.; Robinson, C.; To, Z.; Wren, K.; Banken, L.; Buhles, W.; \& Brown, F. (2000). 
Valganciclovir results in improved oral absorption of ganciclovir in liver transplant recipients. Antimicrob Agents Chemother, 44(10):2811-2815.

Privat de Garilhe, M., \& De Rudder, J. (1964). Effect of 2 arabinose nucleoside on the multiplication of herpes viruse and vairus and vaccine in cell culture. C R Hebd Seances Acad Sci, 259: 2725-2728.

Pue, M.A., \& Benet, L .Z. (1993). Pharmacokinetics of famciclovir in man. Antiviral Chem. Chemother, 4(Suppl. 1), 47-55.

Pue, M.A.; Pratt, S.K.; Fairless, A.J.; Fowles, S.; Laroche, J.; Georgiou, P.; \& Prince, W. (1994). Linear pharmacokinetics of penciclovir following administration of single oral doses of famciclovir 125, 250, 500 and $750 \mathrm{mg}$ to healthy volunteers. J Antimicrob Chemother, 33(1):119-127

Ralevic, V. (2009). Purines as neurotransmitters and neuromodulators in blood vessels. Curr Vasc Pharmacol, 7(1):3-14.

Rajalakshmi, R.; Kumari, R.; \& Thappa, D.M. (2010). Acyclovir versus valacyclovir. Indian J Dermatol Venereol Leprol, 76(4):439-444.

Rashidi, M.R. (1996). In vitro oxidation of purins by hepatic molybdenum hydroylases. Ph.D. Thesis, University of Bradford, UK.

Rashidi, M.R.; Smith, J.A.; Clarke, S.E.; \& Beedham, C. (1997). In vitro oxidation of famciclovir and 6-deoxypenciclovir by aldehyde oxidase from human, guinea pig, rabbit, and rat liver. Drug Metab Dispos, 25(7):805-813.

Rashidi, M.R.; Beedham, C.; Smith, J.S.; \& Davaran, S. (2007). In vitro study of 6mercaptopurine oxidation catalysed by aldehyde oxidase and xanthine oxidase. Drug Metab Pharmacokinet, 22(4):299-306.

Rashidi, M.R.; \& Nazemiyeh, H. (2010). Inhibitory effects of flavonoids on molybdenum hydroxylases activity. Expert Opin Drug Metab Toxicol, 6(2):133-152.

Rider, B.J. (2008). Mercaptopurine, xPharm: The Comprehensive Pharmacology Reference, 1-4.

Rose, K. M.; \& Jacob, S. T. (1978). Selective inhibition of RNA polyadenylation by Ara-ATP in vitro: a possible mechanism for antiviral action of Ara-A. Biochem Biophys Res Commun, 81(4): 1418-1424.

Safrin, S. \& Phan, L. (1993). In vitro activity of penciclovir against clinical isolates of acyclovir-resistant and foscarnet-resistant herpes simplex virus. Antimicrob Agents Chemother, 37(10): 2241-2243.

Schwartz, R.; Stack, J.; \& Dameshek, W. (1958). Effect of 6-mercaptopurine on antibody production. Proc Soc Exp Biol Med, 99(1):164-167.

Shaw, G. (1984). In: Comprehensive Heterocyclic Chemistry (Ed. K.T. Potts), Vol. 5, Pergamon Press, pp. 499-605.

Shen, W.; Kim, J.S.; Kish, P.E.; Zhang, J.; Mitchell, S.; Gentry, B.G.; Breitenbach, J.M.; Drach, J.C.; \& Hilfinger, J. (2009). Design and synthesis of vidarabine prodrugs as antiviral agents. Bioorg Med Chem Lett, 19(3):792-796 .

Shipman, C.,Jr., Smith S.H.; Carlson, R.H.; \& Drach, J.C. (1976). Antiviral activity of arabinosyladenine and arabinosylhypoxanthine in herpes simplex virus-infected KB cells: selective inhibition of viral deoxyribonucleic acid synthesis in synchronized suspension cultures. Antimicrob Agents Chemother, 9(1): 120-7. 
Stredansky, M.; Pizzariello, A.; Miertus, S.; \& Svorc, J. (2000). Selective and Sensitive Biosensor for Theophylline Based on Xanthine Oxidase Electrode, Anal. Biochem, 285, 225-229.

Tjia, J.F., Colbert, J.; Back, D.J. (1996). Theophylline metabolism in human liver microsomes: inhibition studies. J Pharmacol Exp Ther, 276(3): 912-917.

Van Scoik, K.G.; Johnson, C.A.; \& Porter, W.R. (1985). The pharmacology and metabolism of the thiopurine drugs 6-mercaptopurine and azathioprine. Drug Metab Rev, 16(12):157-174.

Vere Hodge, R.A.; Sutton, D.; Boyd, M.R.; Harnden, M.R.; \& Jarvest, R.L. (1989). Selection of an oral prodrug (BRL 42810; famciclovir) for the antiherpesvirus agent BRL 39123 [9-(4-hydroxy-3-hydroxymethylbut-l-yl)guanine; penciclovir]. Antimicrob Agents Chemother, 33(10):1765-1773.

Vere Hodge, R. A.; \& Cheng, Y.C. (1993). The mode of action of penciclovir. Antiviral Chem. Chemother, 4(Suppl. 1), 13-24.

Vielhaber, M. M.; \& Kavuru, M. (2001). Should we still be using theophylline to treat asthma? Cleve Clin J Med, 68(8): 681.

Vince, R.; Hua, M.; Brownell, J.; Daluge, S.; Lee, F.; Shannon, W.M.; Lavell, G.C.; Qualls, J.; Weislow, O.S.; Kiser, R.; Canonico, P.G.; Schultz, R.H.; Narayanan, V.L.; Mayo, J.G.; Shoemaker, R.H.; \& Boyd, M.R. (1988). Potent and selective activity of a new carbocyclic nucleotide analogue (carbovir; NSC 614846) against human immunodeficiency virus in vitro. Biochem Biophys Res Comm,156:1046-53.

Vince, R.; Brownell, J.; \& Beers, S.A. (1995). 6-Deoxycarbovir: a xanthine oxidase activated prodrug of carbovir, Nucleosides Nucleotides, 14, 39-44.

Whitley, R.J.; Tucker, B.C.; Kinkel, A.W.; Barton, N.H.; Pass, R.F.; Whelchel, J.D.; Cobbs, C.G.; Diethelm, A.G.; \& Buchanan, R.A. (1980). Pharmacology, tolerance, and antiviral activity of vidarabine monophosphate in humans. Antimicrob Agents Chemother, 18(5):709-715.

Whitley, R.J.; Nahmias, A.J.; Soong, S.J.; Galasso, G.G.; Fleming, C.L.; \& Alford, C.A. (1980). Vidarabine therapy of neonatal herpes simplex virus infection. Pediatrics. 66(4):495501.

Whitley, R.; Alford, C.; Hess, F.; \& Buchanan, R. (1980). Vidarabine: a preliminary review of its pharmacological properties and therapeutic use. Drugs. 20(4):267-282.

Woster, P.M. (2007). Antiviral agents and protease inhibitors, In: Foy's principles of medicinal chemistry, W.O. Foye, T.L. Lemke, D.A. Williams (Eds.), Lippincott, Williams \& Wilkins, p. 1213.

Winkler, I.; Winkelmann, E.; Scholl, T.; Rosner, M.; Jahne, G.; \& Helsberg, M. (1990). Antiviral activity and pharmacokinetics of HOE 602, an acyclic nucleoside, in animal models. Antiviral Res, 14(2):61-73.

Yao, C.; Kunze, K.L.; Kharasch, E.D.; Wang, Y.; Trager, W.F.; Ragueneau, I.; \& Levy, R.H. (2001). Fluvoxamine-theophylline interaction: gap between in vitro and in vivo inhibition constants toward cytochrome P4501A2. Clin Pharmacol Ther, 70(5): 415-24. 
Zimm, S.; Grygiel, J.J.; Strong, J.M.; Monks, T.J.; \& Poplack, D.G. (1984). Identification of 6mercaptopurine riboside in patients receiving 6-mercaptopurine as a prolonged intravenous infusion. Biochem Pharmacol, 33(24):4089-4092. 


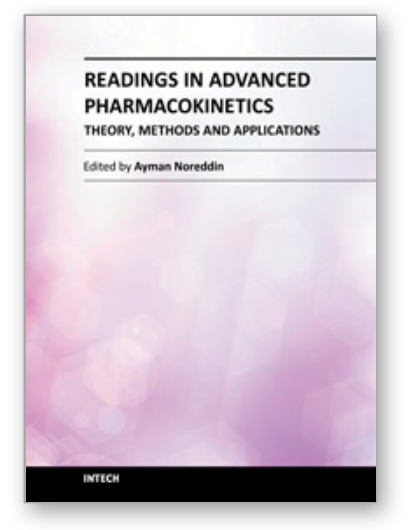

\section{Readings in Advanced Pharmacokinetics - Theory, Methods and Applications}

Edited by Dr. Ayman Noreddin

ISBN 978-953-51-0533-6

Hard cover, 378 pages

Publisher InTech

Published online 20, April, 2012

Published in print edition April, 2012

This book, "Readings in Advanced Pharmacokinetics - Theory, Methods and Applications", covers up to date information and practical topics related to the study of drug pharmacokinetics in humans and in animals. The book is designed to offer scientists, clinicians and researchers a choice to logically build their knowledge in pharmacokinetics from basic concepts to advanced applications. This book is organized into two sections. The first section discusses advanced theories that include a wide range of topics; from bioequivalence studies, pharmacogenomics in relation to pharmacokinetics, computer based simulation concepts to drug interactions of herbal medicines and veterinary pharmacokinetics. The second section advances theory to practice offering several examples of methods and applications in advanced pharmacokinetics.

\section{How to reference}

In order to correctly reference this scholarly work, feel free to copy and paste the following:

Mohammad-Reza Rashidi and Roghiyeh Pashaei-Asl (2012). Role of Aldehyde Oxidase and Xanthine Oxidase in the Metabolism of Purine-Related Drugs, Readings in Advanced Pharmacokinetics - Theory, Methods and Applications, Dr. Ayman Noreddin (Ed.), ISBN: 978-953-51-0533-6, InTech, Available from: http://www.intechopen.com/books/readings-in-advanced-pharmacokinetics-theory-methods-andapplications/role-of-aldehyde-oxidase-and-xanthine-oxidase-in-the-metabolism-of-purine-related-drugs

\section{INTECH}

open science | open minds

\author{
InTech Europe \\ University Campus STeP Ri \\ Slavka Krautzeka 83/A \\ 51000 Rijeka, Croatia \\ Phone: +385 (51) 770447 \\ Fax: +385 (51) 686166 \\ www.intechopen.com
}

\author{
InTech China \\ Unit 405, Office Block, Hotel Equatorial Shanghai \\ No.65, Yan An Road (West), Shanghai, 200040, China \\ 中国上海市延安西路65号上海国际贵都大饭店办公楼 405 单元 \\ Phone: +86-21-62489820 \\ Fax: +86-21-62489821
}


(C) 2012 The Author(s). Licensee IntechOpen. This is an open access article distributed under the terms of the Creative Commons Attribution 3.0 License, which permits unrestricted use, distribution, and reproduction in any medium, provided the original work is properly cited. 